\title{
Specificity and Differential Object Marking in Spanish*
}

\section{Manuel Leonetti}

Universidad de Alcalá. Departamento de Filología

C/Trinidad, 5. 28801 Alcalá de Henares (Madrid). Spain

manuel.leonetti@uah.es

\begin{abstract}
The use of the preposition $a$ with direct objects in Spanish is a well known instance of the general phenomenon of Differential Object Marking (DOM). In Spanish grammars the insertion of $a$ is usually presented as dependent on two basic factors: animacy and referentiality/specificity. The correlation between the object marker and specificity is not systematic, basically because animacy — and not specificity — is the dominant trigger for DOM in Spanish, but a number of facts still indicate that the presence of $a$ tends to be associated with specific readings. In order to account for these facts without positing any [+specific] feature in the linguistic meaning of $a$, I try to show that it contributes to utterance interpretation as an internal topic marker. This seems to be the simplest way to derive «specificity effects», and to account for the crosslinguistic similarities between DOM and other grammatical phenomena (topicalization, clitic doubling, scrambling).
\end{abstract}

Key words: specificity, animacy, topicality, object marking, inference.

\section{Table of Contents}

\section{Preliminaries \\ 4. Specificity in grammatical theory \\ 2. $A+$ direct object References}

3. Specificity and topicality

* I am grateful to the participants at the workshop «Semantic and Syntactic Aspects of Specificity in Romance Languages» (Konstanz, October 2002) and to two anonymous reviewers of Catalan Journal of Linguistics for very useful and thought-provoking comments, as well as to Vicky Escandell-Vidal and Olga Fernández-Soriano for helpful discussion on an earlier draft. Thanks also to Begoña Vicente for patiently correcting my English. All remaining errors are exclusively mine. A previous version of this paper appeared as «Specificity and Object Marking: the Case of Spanish $a »$ in K. Von Heusinger and G. Kaiser (eds.), Proceedings of the Workshop «Semantic and Syntactic Aspects of Specificity in Romance Languages», Arbeitspapier 113. Fachbereich Sprachwissenschaft, Universität Konstanz, 67-101. This research was supported by the Spanish Ministerio de Ciencia y Tecnología through a DGICYT project (PB98/0707 «Gramática e interpretación en la teoría de la relevancia»). 


\section{Preliminaries}

It is well known that several languages use certain grammatical devices as object markers that are in some sense associated with the Specific / Non-Specific distinction. Spanish is one of them, and Romanian, Turkish, Persian or Hindi are frequently mentioned as other representative cases of the general phenomenon which, following Georg Bossong's proposal, we call Differential Object Marking (DOM) ${ }^{1}$. My aim in this paper will be that of determining what is the particular contribution of DOM to utterance interpretation in Spanish, and how specificity is related to it. I would like to begin by presenting some basic assumptions about the Semantics / Pragmatics interface and on the notion of specificity, in order to use them later in the analysis of the Spanish prepositional accusative. I intend to show that, although the correlation between the accusative marker and specificity is far from clear, basically because animacy — and not specificity — is the dominant trigger for DOM in Spanish, a number of facts still indicate that the prepositional accusative tends to be associated with specific readings, in a way which is not unrelated to what happens in scrambling and clitic doubling constructions. Far from deriving from some [+ specific] feature inherent in the meaning of $a$, such facts can be shown to be a consequence of a different basic semantic feature that should allow us to bring together most of the grammatical phenomena that are sensitive to specificity. Some closing remarks on specificity in grammatical structure will sum up the discussion.

I will defend the general hypothesis that when natural languages encode specificity, they do it inside DP structure only (basically by means of determiners), and not in other positions; as a consequence, other alleged specificity markers outside DP structure are actually modality indicators or information structure markers. In these cases, the markers simply force a specific reading in certain DPs without encoding specificity themselves. Clarifying this issue should allow us to have a more precise view of the role of specificity in grammatical systems.

The basic assumptions are as follows. First, I assume Sperber and Wilson's distinction between linguistic meaning (logical form, in Relevance-theoretic terms) and explicatures as two different semantic levels (Sperber and Wilson 1986). While linguistic meaning yields a linguistically-encoded semantic representation - the output of the grammatical system - and only provides an incomplete schema for the inferential construction of a full proposition, explicatures are the propositions explicitly communicated by an utterance and are obtained by fleshing out the logical forms encoded in it. Explicatures are derived from logical forms by linguistic decoding, on the one hand, and by pragmatic inference based on contextual information, on the other. In short, we have two levels of meaning: one linguistically encoded in lexical items or in syntactic positions, and the other inferentially obtained from the first, thus constituting a partially pragmatically derived level of representation.

It is important to clarify that it is explicatures, and NOT linguistic meaning, that formal semanticists work on when they try to give an account of the semantic content of utterances. But we should bear in mind that an important part of the 
explicature is pragmatically inferred, and thus is not to be considered as linguistically encoded meaning. A brief example will be enough to illustrate this theoretical distinction. In (1) there is a typical case of associative anaphora:

\section{(1) It is a very good restaurant, but the prices are too high.}

The definite DP the prices is interpreted as anaphorically related to the DP the restaurant, but they are not coreferential. The anaphoric link between them is easily recovered from the encyclopedic knowledge that speakers have about restaurants (Prince 1992). Such a link becomes a part of the propositional representation - the explicature - of the utterance (i.e. «...but the prices of the aforementioned restaurant are too high»). But we would not want to say that the anaphoric dependence is encoded in the meaning of the definite article the (even if we were to accept the familiarity hypothesis for the linguistic meaning of the). This dependence is in fact inferred on the basis of some general pragmatic principle. In any case, recovering an associative anaphoric link in (1) is the easiest way to obey the semantic instruction encoded by the. The article simply encodes an instruction to find a referent that is uniquely identifiable (and this is linguistic meaning), and the remaining part of the interpretation, i.e. the recovery of the associative link between restaurant and prices and the anaphoric dependence, is pragmatically inferred in the development of the logical form for (1) into an explicature. This division of labour between semantics and pragmatics is one of the assumptions I will rely on in the analysis of specificity. The crucial question is, thus, what is encoded by the grammatical system and what is inferred, when we talk about specific readings of DPs.

The second basic assumption concerns the status of indefinites, in particular specific indefinites. I will assume that they are not lexically ambiguous, despite their exceptional scope properties, and that, unlike definites, they do not guarantee that there is a uniquely identifiable referent, so that the only condition they impose is that the value assigned to their discourse referent be an element of the set denoted by the description (cf. Farkas 2002). Indefinite DPs may or may not contribute conditions that specify such a value: specific readings arise when the choice of referent is presented as heavily constrained, and non-specific readings arise when the choice is presented as being relatively free. As Farkas (2002: 214) puts it, «... specificity turns out to be an epiphenomenon connected to a family of distinctions that are marked differently in different languages». I am especially interested in this characterization of specificity as an epiphenomenon, because it is often not encoded by grammar or by lexical items, but just inferred in the development of propositional explicatures. From this perspective specificity is described as a derived pragmatic effect, and not as an interpretable feature. Of course, I do not intend to deny the semantic nature of specificity in certain cases: there are languages that show clear manifestations of the specific / non-specific distinction in their determiner systems, and Haspelmath (1997) and Lyons (1999), for instance, present several examples of this. But in many languages specificity is not a feature of the linguistic semantics of any item or construction. Thus, languages can display so called «specificity effects», but that does not imply that specificity is a 
feature of their semantics. The point I want to make is that the situation we find with the notion of specificity is essentially the same that we find with the notion of definiteness: it is not encoded in the same way and to the same extent in all languages. In languages that lack definite articles, like Russian, definiteness has to be inferred on the basis of different grammatical markers (case markers, word order, agreement...), and the same happens with specificity in many of the cases we are analysing. The crucial question is: when is specificity grammatically or lexically encoded, and when is it inferred?

At least since Farkas (1995), it is usual to distinguish among different types of specificity: partitive specificity, scopal specificity, epistemic specificity, and we could add «relative specificity», following von Heusinger (2001, 2002). I would like to discuss this issue briefly in order to make my point clearer. It would certainly be desirable to find a precise definition of specificity that will be relevant for DOM in Spanish. Unfortunately, none of the mentioned types of specificity seems to be systematically connected to DOM. With respect to partitive specificity, I believe that partitivity is simply one more way to obtain a specific interpretation when syntax forces it and contextual information makes available the recovery of a given domain of quantification, but it is not encoded by any of the constructions characterized by specificity effects; moreover, it is compatible with non-specific readings (cf. Abbott 1995). As argued below in $\$ 2.2$, scopal specificity is not systematically linked to DOM in Spanish either, and does not seem to play a central role in the distribution of $a$. As for epistemic specificity, I share the observation that having something in mind or being able to identify it are not necessarily prerequisites for specificity (Geurts 2002, von Heusinger 2001, 2002), and again those conditions are not relevant for an account of DOM. I agree with Rouchota (1994) in assuming that, instead of the speaker's mental state, what is decisive for specificity is the speaker's intention to make manifest to the audience that the DP is employed to refer to a particular referent. This means choosing a purely pragmatic approach to specificity, which I am sympathetic to, although the problem with such an approach is the obvious difficulty to connect it to the syntactic or semantic tools needed in linguistic analysis.

Finally, in order to cover all the different types of specificity mentioned so far, including so-called cases of «relative specificity», we could resort to von Heusinger's $(2001,2002)$ new characterization of the notion as the property of a DP being referentially anchored to another object in the discourse. According to von Heusinger, in a specific expression the referent is fixed or determined by being functionally linked to the speaker or to a referential expression contained in the same sentence: for instance, in a sentence like William didn't see a book (von Heusinger 2002: 271), there are two specific interpretations of the indefinite DP, one of them anchored to the speaker, and the other one anchored to the subject of the sentence. The crucial fact is that a specific expression does not have to be «absolutely» related to the speaker, as the «certainty of the speaker towards the referent» is not a necessary ingredient of specific interpretations. This provides us with a general definition that seems to be able to cover different features of specificity. From now on I will use the term specific in a sense quite close to referentially anchored. 
I believe that an analysis of DOM in Spanish requires a general notion of specificity, instead of one of the particular types mentioned above, basically for two reasons: first, these types of specificity are nothing more than contextual results of the inferential development of the linguistic semantics in indefinites; second, none of the grammatical devices I will discuss is exclusively linked to a particular type of specific interpretation, as far as I can tell.

The third basic assumption is that, as many authors have pointed out (Jäger 1995a, Erteschik-Shir 1997, Yeom 1998, Büring 2001, Portner and Yabushita 2001, Geurts 2002), specific readings of indefinites are in some way related to the topical status of the DP. Two very influential works paved the way for such a point of view: Enç (1991) and Diesing (1992). These two contributions popularised the idea that specificity is essentially connected with discourse linking or presuppositionality. In the nineties the idea spread that Diesing's findings were basically a matter of information structure, and this caused the notion of topic to become a crucial concept for the analysis of specificity in several contexts (see for instance Raposo and Uriagereka 1995 and Jäger 1995a). So the central question should now be Why is the concept of 'topic' important for an understanding of specificity? I assume that it is important, although not exactly for the same reasons that one finds in the literature: instead of taking for granted that all specific indefinites are topical, or presuppositional, or background information, I would simply say that the topical status forces the specific interpretation of an indefinite ${ }^{2}$. This is a crucial assumption when looking at the interpretive effects of syntactic devices such as scrambling, clitic doubling, subject preposing and DOM. I will come back to this issue later (section 3).

Now that these assumptions have been presented, I can proceed to the analysis of the prepositional accusative in Spanish and its interpretive role.

\section{2. $A+$ direct object}

\subsection{In favour of a as specificity marker}

It is a well known fact that specificity is often reflected in the morphological marking of the direct object, and Spanish is usually presented as a language that distinguishes specific objects and non-specific objects by means of the preposition $a$. $A$ is the same preposition used for indirect objects or datives; this is a widespread feature among the languages that resort to prepositions for DOM. It is true that the insertion of $a$ has significant effects on specificity, but the whole issue deserves a detailed analysis before we can clarify the nature of the contribution of $a$ to utterance interpretation. Let me first present some data that seem to indicate that the prepositional marker is indeed a specificity indicator. The examples are mainly

2. In certain contexts the topical status forces a generic reading, instead of a specific one, but recall that both specific and generic interpretations of indefinites belong to the family of strong interpretations, while non specific interpretations are typically weak. So it is the strong / weak distinction that actually correlates with topic-focus structure. See Cohen and Erteschik-Shir (2002) for an extension to the interpretation of bare plurals in English. 
taken from Brugè (2000), Brugè and Brugger (1996), Laca (1987), Leonetti (1999) and Torrego (1998) and (1999).

\subsubsection{A in opaque contexts}

Examples like those in (2) are the most frequently mentioned argument for a connection between the prepositional accusative and specificity. They seem to indicate that the reading of the object DP is in fact specific with $a$ and non-specific without $a^{3}$ :

a. Necesita a una enfermera que pasa la mañana con ella./

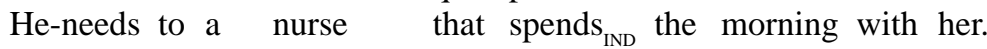
Necesita una enfermera que pase la mañana con ella.

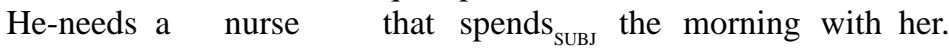
'He needs a nurse \{that spends the morning with her./to spend the morning with her.\}'

b. *Necesitan a camarero./ Necesitan camarero. They-need to waiter. / They-need waiter. 'They need a waiter.'

c. Busca a un médico. / Busca un médico. (S)he-looks-for to a doctor. / S(he)-looks-for a doctor. '(S)he is looking for a doctor.'

Notice that in (2a) the mood of the subordinate verb in the relative clause reinforces the effect of DOM: the object is preceded by $a$, and specific, in the first case, where the verb is in the indicative mood, whereas the absence of $a$ makes the object non-specific in the second case, where the verb is in the subjunctive mood. The example with $a$ entails that a particular nurse exists that spends the morning with her; such an entailment is not licensed in the other case. The speaker is supposed to be willing to refer to that particular nurse when the object is marked. The contrast in (2b) is due to the incompatibility between $a$ and a bare singular noun, which is an expected result, if we assume that bare nouns can never receive a specific reading and therefore should not be preceded by $a$. Finally, the contrast in (2c) is a classical example of the correlation of $a$ with a specific reading, and of the absence of the preposition with a non-specific one (again, an existential entailment is licensed only in the first case). Nevertheless, it must be pointed out that $a$ is not incompatible with a non-specific reading in Busca a un médico, and so the sentence remains ambiguous.

\subsubsection{Partitive constructions}

It has been repeatedly pointed out that [+human] partitive object DPs take $a$ obligatorily, as is shown in (3) (from Brugè and Brugger 1996):

3. From now on I will translate $a$ as to in the English word-by-word version of the examples. 
(3) He visto *(a) muchas de esas estudiantes.
I-have seen *(to) many of those students.
'I have seen many of those students.'

This is a natural consequence of the typically specific interpretation that partitives receive. Since partitives include a definite or familiar domain of quantification for the indefinite, they are expected to behave like definite DPs with respect to accusative marking (Recall that definites require the insertion of $a$, except in certain generic interpretations).

\subsubsection{Incompatibility with existential constructions}

The construction with haber plus postverbal DP represents the canonical existential context in Spanish, with its associated definiteness effect. If haber takes only weak DPs and specific indefinites are a type of strong DP, then one should expect that $a$, being a specificity marker, should be ungrammatical in such contexts, and in fact it is (this is a very clear and strong restriction, in the sense that $a$ is completely excluded).
(4) Había
(*a) una enfermera.
There-was
(*to) a
nurse.
'There was a nurse.'

Another existential context that gives rise to a definiteness effect is provided by the verb tener, «have» (cf. ?Este coche tiene el airbag «This car has the airbag»), and again it excludes the presence of $a$, as shown in (5):
(5) Ella tenía (*a) un hermano.
She had (*to) a brother.
'She had a brother.'

In this case both the restriction against definites and the correlated restriction against the presence of $a$ disappear when tener is followed by a secondary predication structure, an effect I will come back to later ${ }^{4}$ :

4. As a reviewer noticed, the examples in (6) are not the only ones where the definiteness restriction on tener fails to apply. The same happens in cases like (i) and (ii), where there is no secondary predication:

(i) Estos dos coches tienen el mismo airbag.

These two cars have the same airbag

(ii) María aún tiene el coche que le regalamos.

Mary still has the car that to-her we-gave

I think that it is due to independent factors: as for (i), the presence of mismo 'same' as a modifier gives rise to several counterexamples for the definiteness restriction, even with existential haber, possibly because it favours a reading of the DP as a type; in (ii), on the other hand, tener shows a kind of possessive interpretation that cancels the definiteness restriction. 
(6) Este coche tiene el airbag estropeado. / Ella tenía a un hermano en This car has the airbag broken. / She had to a brother in la cárcel.

the prison.

'This car's airbag does not work.' / 'She had a brother in prison.'

The data in (4), (5) and (6) indicate that there is a systematic correlation between the presence of $a$ and the definiteness effect, and this is a relevant fact because definiteness restrictions in general have to do with specificity or some related notion, as indicated by Enç (1991). Thus, the provisional conclusion should be something like this: $a$ appears with specific DPs (or strong DPs) -in a very general sense of specific- This reflects the central intuition that is usually mentioned in Spanish grammars, although it is obviously not the whole story about $a$.

\subsection{Against a as specificity marker}

The main problem for a characterization of $a$ as a specificity marker is also well known: as many authors have concluded, the basic feature the prepositional accusative is correlated to is animacy, or a [+human] feature, to be more precise, and not specificity or referentiality (see, for instance, Brugè and Brugger 1996). Animacy and specificity (i.e. the two prominence scales of animacy and definiteness / specificity that make up the basis for research on DOM) interact in quite an intricate way, and I do not intend to go into that issue in detail ${ }^{5}$. I will limit myself to the connection between DOM and specificity. The strongest argument we can offer against characterizing $a$ as a specificity marker is the possibility of using it with non-specific indefinite DPs that still require the preposition because of their [+human] feature. The examples in (7) to (10) illustrate the combination of $a$ with non-specific indefinites:

a. Está buscando

a alguien. / No está buscando (S)he-is looking-for to someone. / Not (s)he-is looking-for

a nadie.

to anyone.

'(S)he is looking for someone.' / ' '(S)he is not looking for anyone.'

b. Necesitan (a) un ayudante que sepa inglés. They-need (to) an assistant that speaks subj $_{\text {English. }}$ 'They need an assistant that speaks English.'

(8) a. Cada estudiante entrevistará a un personaje conocido.

Each student will-interview to a celebrity.

'Each student will interview a celebrity.'

5. But see Aissen (2003), von Heusinger and Kaiser (2003), and Farkas and von Heusinger (2003) for a discussion of the proper way to deal with several prominence scales simultaneously in the analysis of DOM. 
b. Todas las niñas admiraban a algún cantante.

Every the child (fem) admired to some singer.

'Every child admired some singer.'

(9) a. Toda persona que contrata (a) un inmigrante...

Every person that hires (to) an immigrant worker...

'Every person that hires an immigrant worker...'

b. Conoces (a) muchas personas para llevar aquí tan poco tiempo.

You-know to many persons to be here so few time.

'You know a lot of people considering you haven't been here for long.'

(10) a. La empresa ha contratado (a) trabajadores con experiencia. The company has hired to workers with experience.

'The company has hired experienced workers.'

b. No conozco (a) candidatos con esas características.

Not I-know to candidates with those features.

'I don't know candidates with those features.'

In (7) $a$ precedes indefinite pronouns like alguien ('someone') and nadie ('anyone') that are interpreted non-specifically (but notice that they denote human beings only), or indefinite DPs with subjunctive relative clauses - one of the classical ways of signalling non-specific readings in Romance languages - (again with human denotata). In (8) the prepositional marker is obligatory and still the object DPs (with human denotata) can be naturally interpreted as narrow scope and as non-specific indefinites. In (9), following Bosque (2001) and Sánchez López (1995), I have reproduced two grammatical contexts that require non-specific indefinites, namely a «donkey sentence» fragment in (9a) and an indefinite DP with a concessive subordinate clause in $(9 \mathrm{~b})^{6}$; in both cases $a$ is perfectly grammatical (with human denotata). And finally in (10) $a$ combines with bare plurals, which are not supposed to get specific readings (at first sight, this is contradictory with what we observe in (2b), i.e. that bare nouns cannot be preceded by $a$, but the crucial factor is singularity vs plurality: bare singulars show a more constrained distribution than bare plurals).

We see then that there are good grounds for rejecting accounts of $a$ as a specificity marker and supporting instead [+human] as the semantic feature governing its insertion. Nevertheless, some link with specificity must still exist, if the data in the previous section are correct. So the question is how to integrate two sets of facts that seem to be contradictory in a coherent explanation.

For a correct understanding of the semantic contribution of $a$ we should bear in mind three general points. First, it seems natural to assume that the linguistic mean-

6. This kind of subordinate clause is licensed by the presence of indefinites like mucho(s) ('many') or demasiado(s) ('too much/too many') only if they are non-specific. 
ing encoded by the preposition is some abstract feature that underlies the interaction or combination of specificity and animacy (given that the two scales of definiteness/specificity and animacy control the distribution of DOM in Spanish and many other languages); thus the marker cannot simply mean «human direct object» or «specific direct object». If neither specificity nor animacy are encoded by $a$, something else must be responsible for the interpretive effects of accusative morphology, something that underlies other syntactic phenomena that systematically involve both animacy and definiteness/referentiality scales, like clitic doubling and object shift.

Second, the puzzling situation described above is partly due to the obligatory nature of accusative marking with several verbs in Spanish, and partly to the predominant role of animacy. In the literature on the topic it has been frequently observed that certain verbs require $a$ obligatorily and others just allow its insertion without imposing it (see for instance Pensado 1995:33-35 and Torrego 1998:23). Thus, verbs like saludar ('greet'), odiar ('hate'), insultar ('insult'), castigar ('punish'), sobornar ('bribe') or atacar ('attack') impose $a$ on their animate objects, but verbs like encontrar ('find'), buscar ('look for'), esconder ('hide') or ver ('see') admit non-overtly case-marked objects. The two classes of verbs differ in several respects, basically in their aspectual properties, the affectedness of the object and the agentivity of the subject - three of the usual parameters that control the presence of $a$. Bearing in mind this fact may help us to look again at the examples in (7) to (10).

As for the use of $a$ with non-specific indefinites, it is important to notice that the verbs in the examples in (8), entrevistar ('interview') and admirar ('admire'), require the obligatory presence of $a$, which implies that the semantic contribution of the marker in these cases is no longer relevant for interpretive purposes. When $a$ is automatically selected by the verb, it becomes an inert, non-distinctive morphological device: this is one of the reasons why $a$ occurs with non-specific indefinites as well. Cases of partial grammaticalization of object markers are attested in other languages with identical effects ${ }^{7}$ : Lidz (1999), for instance, shows that obligatorily case-marked objects in Kannada have the same range of interpretations as non-case-marked objects, a fact that seems to be a result of the historical expansion of DOM in the language, and Franco and Mejías-Bikandi (1999:115), focusing on clitic doubling in Basque Country Spanish, state that «[o]vert object morphology, whether case-marking morphology on the noun, or object agreement morphology on the verb, has a systematic effect on the interpretation of indefinite objects in those cases where object morphology is apparently optional».

7. The process of grammaticalization of the object marker is slowly spreading in Spanish, and certain dialects are extending the use of $a$ even to some inanimate and abstract nouns, according to Company (2002). This further complicates the analysis of its interpretive effects, and takes some authors to deny the relevance of the [+human] feature (cf. Delbecque 1999). See Aissen (2003: §5.4) for an overview of the historical expansion of DOM in Spanish, and Sadler (2002) for an analysis of the grammaticalization process of the direct object marker $-o$ in Japanese that shows how the use of $-o$ was mainly correlated to factors like animacy, referentiality and the importance of referents in Classical Japanese, and how such a correlation disappeared as $o$-marking increased to give rise to a general object marker in Modern Japanese. 
From a wider perspective, it can be observed that the obligatory nature of a syntactic rule usually cancels the semantic effects the rule could have. As Adger (1996:117) puts it in his analysis of the interpretation of subjects in Italian, «...optional movement seems to correlate with different interpretations for the resulting structures; when movement is obligatory, on the other hand, the single resulting structure seems to have both of the possible interpretations assigned to the two structures given by optional movement.»

Such considerations on movement rules apply, mutatis mutandis, to case-marking as well. As a consequence, the semantic contribution of $a$ (and its association with specificity) is not systematic across all contexts. In order to throw some light on the specificity issue, then, the contexts that are worth concentrating on are those where there is a possibility to choose between using and not using the preposition: only there will the basic properties of $a$ be revealed. In the next sections I will focus on such contexts.

In (7), (9) and (10) $a$ is not obligatorily selected by the verb, but again we find no systematic semantic effects: with the intensional verbs in (7) it allows non-specific readings, and with extensional verbs such as contratar ('hire') and conocer ('know') in (9) and (10) the non-specific reading is in fact the only possibility. In the first case the presence of $a$ is forced by the [+human] feature and the pronominal nature of alguien ('someone') and nadie ('no one'), which block the choice between $a$ and $\varnothing$, thus cancelling the semantic contribution of the preposition. In the second case the sentential context excludes any plausible specific interpretation, with similar consequences for the contribution of $a$ : in (9a) it is genericity that precludes a specific interpretation of the indefinite object, in (9b) it is the insertion of the concessive clause, and in (10) it is the impossibility of assigning a specific interpretation to a bare plural. Why does $a$ occur, then? Because, as mentioned before, animacy overrides all other factors in the DOM system in Spanish, and all the indefinite objects in the example are [+human]. With [+human] objects, thus, DOM remains optional only with non-pronominal DPs and with a small group of verbs.

Finally, it must be noticed that even in the limited contexts where the choice between $a$ and $\varnothing$ is allowed there is usually not an absolute contrast, but rather a sort of «privative opposition»: while $a$-case-marked objects may admit both strong and weak interpretations in most cases, non-case-marked objects take only weak interpretations. In (11), for instance, a specific reading arises only with $a$, as has often been pointed out, but the non-specific reading is available both with $a$ and without it.

\section{(11) Necesitaban (a) un especialista.}

They-needed (to) a specialist.

'They needed a specialist.'

The privative opposition between $a$ and $\varnothing$ is hardly surprising, if one thinks of similar facts like those we find in the interpretation of preverbal and postverbal indefinite subjects in Romance: when both positions are available for the subject, i.e. 
typically with unaccusative predicates, the preverbal one tends to force strong readings for indefinites, while the postverbal one allows strong or weak readings, so that there is one kind of reading that is compatible with the two positions (Adger 1996).

Facts like these show how the semantic contribution of $a$ is obscured and distorted both by the predominance of animacy and by the selection properties of verbs. Bearing in mind such issues, we should now address two crucial questions: a) Is there a notion that allows us to put together specificity and animacy in DOM systems in some principled way? And b) How can we deal with the (non-systematic) connection that still exists between $a$-marking and specificity, i.e. why are specific interpretations linked in some way to $a$-marked objects?

\subsection{A as a topic marker}

A path that is worth exploring to find a suitable answer to the aforementioned questions is the one that links specificity and topicality. Several authors have resorted to the notion of Topicality in their research on specific readings of indefinites. This allows me to exploit an obvious connection with the idea that $a$ is actually a sort of topicality marker, an idea which is not new and has been already defended in Laca (1987). Before reviewing the arguments offered by Laca and some other additional data, it is important to recall that topic is being used here in the «aboutness» sense, i.e., as an anchor for new assertions, rather than in the sense of «familiar, given or old information» (topic is in this sense essentially identical to the notion of link in Vallduví 1992). As referentially independent expressions, topics introduce prominent participants in the discourse. Making a DP a topic indicates that the individualization of its referent is relevant for utterance interpretation. Given this, if, on the one hand, it is possible to show that specificity is an effect of topicality and, on the other, there are reasons to consider $a$ as a topic marker, a plausible answer could be given to our questions. In what follows I am going to review the reasons for taking $a$ to be a topic marker.

\subsubsection{Clitic left-dislocation}

First of all, as Laca (1987), Pensado (1995) and Melis (1995) have pointed out, the preposition is overwhelmingly present in syntactic topicalization structures, i.e., in clitic left-dislocation constructions, even when the non-topicalized counterpart of the sentence allows both a marked or an unmarked object, as in (12) (cf. Ya conocía (a) muchos estudiantes; Habían incluido (a) dos catedráticos en la lista):

(12) a. *(A) muchos estudiantes, ya los conocía. *(To) many students, already them I-knew. 'Many students I already knew.'

b. *(A) dos catedráticos, los habían incluido en la lista. *(To) two professors, them they-had included in the list. 'Two professors they included in the list.' 
The obligatory presence of $a$ in (12) is related to the fact that clitic left-dislocation tends to impose strong interpretations on DPs, and such interpretations are typically associated with $a$. The fact is that $a$ is indeed correlated with clitic left-dislocation, which supports the idea that it behaves like a topic marker. According to Pensado (1995), clitic left-dislocation with personal pronouns is in fact the origin of $a$ as a case-marker for objects in Modern Spanish; thus, $a$ would originally be a topicalization mechanism, and the strong connection it shows now with clitic doubling is a related effect.

\subsubsection{Bare plurals}

Another significant piece of evidence has to do with bare plurals. Spanish does not admit them in preverbal subject position, unless they are modified by restrictive modifiers (adjectives, relative clauses, prepositional complements) or marked as contrastive focus; see the data in (13):

(13) a. $\left\{{ }^{? ? l^{*}}\right.$ Guerrilleros/ ${ }^{\mathrm{OK}}$ Guerrilleros de las FARC fuertemente armados $\}$ \{Guerrilla/ Guerrilla of the FARC strongly armed\} atacaron ayer un puesto de policía en... attacked yesterday a police station at...

'Guerrilla attacked a police station yesterday at... / Strongly armed FARC guerrilla attacked a police station yesterday at...'

b. *Ratas han entrado por este agujero. / RATAS han entrado Rats have entered through this hole. / RATS have entered por este agujero. through this hole.

A striking parallelism between preverbal subject position and case-marked object position is that the same factors seem to license bare plurals in both of them: in fact, bare plurals are excluded in $a$-marked objects, unless they include some kind of restrictive modifier or are focused, as the examples in (14) show (bare plurals may occur as unmarked objects even when they do not obey such conditions).

(14) a. ??Conocemos a profesores / Conocemos a profesores que We-know to teachers. / We-know to teachers that se pasan el fin de semana trabajando. spend the weekend working.

'We know teachers. / We know teachers that spend their weekend working.'

b. ??Detuvieron a hinchas. / Detuvieron a hinchas peligrosos They-arrested to supporters./ They-arrested to supporters dangerous del Atlético.

of Atlético.

'They arrested supporters. / They arrested dangerous Atlético supporters.' 
c. ??En el poblado vi a pescadores. / En el poblado vi a In the village I-saw to fishermen / In the village I-saw to PESCADORES, no a turistas extranjeros. FISHERMEN, not to tourists foreign.

'In the village I saw fishermen. / In the village I saw FISHERMEN, not foreign tourists.'

Following Laca (1996), I assume that the constraints on bare plurals in preverbal subject position are due to the topical nature of such a position and to the impossibility of interpreting bare plurals as topics — with strong readings - in sentenceinternal positions in Romance languages (but see Moreno and Pérez 2001 for some exceptions). If this is basically correct ${ }^{8}$, then the obvious way to explain what happens in marked objects vs unmarked objects is to consider marked objects as topical in some sense: their topical nature is the reason why they exclude unmodified bare plurals. The immediate advantage of this account is that it captures the basic aspects of the distribution of Spanish bare plurals in a simple and unified way.

\subsubsection{Secondary predicates}

Another parallelism with subjects is the correlation of the presence of $a$ and the occurrence of a secondary predicate, even when the object has no [+human] feature; in such cases the object is taken as the predication topic, and the preposition seems to act like a topic marker. I reproduce some examples from Laca (1987), where $a$ forces the hearer to assign a secondary predication structure to the sentence:

(15) a. La tormenta dejó a treinta heridos y a muchos arruinados. The tempest left to thirty wounded and to many ruined. 'The tempest left thirty persons wounded and many ruined.'

b. Juan tiene a un hermano enfermo.

Juan has to a brother ill.

'Juan has a brother that is ill now.'

The generalization that emerges from the observation of all these facts is that marked objects behave in many respects like subjects, in particular topical subjects. Such an analogy with subjects is actually at the heart of the DOM phenomenon: as Aissen (2003) puts it, the higher in prominence a direct object is (in the scales of animacy and definiteness), the more likely it is to be overtly case-marked, which means that the closer it is to the typical properties of subjects (referential autonomy, agentivity), the more likely it is to be overtly case-marked (Laca 1987: 72-74). Topicality seems to be a plausible way to characterize what underlies the interaction of animacy and definiteness, as well as the similarities between subjects and marked objects. 


\subsubsection{Individualization and genericity}

A look at the sentence pairs in (16)-(19) confirms that the presence of $a$ has an effect on the interpretation of the object DP, which is not always clearly reducible to specificity (notice that the preposition is not obligatory in these sentences, except in $(19 a))^{9}$.

(16) a. Juan ha visto a muchas chicas.

Juan has seen to many girls.

b. Juan ha visto muchas chicas.

'Juan has seen many girls.'

(17) a. Juan mató a un tigre.

Juan killed to a tiger.

b. Juan mató un tigre.

'Juan killed a tiger.'

(18) a. Estaba dibujando a una niña.

(S)he-was drawing to a child.

b. Estaba dibujando una niña.

'(S)he was drawing a child.'

(19) a. Pilar siempre contrata *(a) un chico cuando es guapo. Pilar always hires to a boy when he-is handsome.

b. Pilar siempre contrata (a) una canguro cuando se va de viaje. Pilar always hires to a babysitter when she-travels.

According to Brugè (2000), the presence of $a$ in (16a) forces a D-linked reading of the object (cf. Pesetsky 1987), a reading that is impossible in (16b). I would rather say that the D-linked (or partitive) reading of muchas chicas ('many girls') seems to be just one possible interpretation for (16a), but not the only one - though probably the most natural one- The girls mentioned in the example could be a group of specific girls, but not necessarily taken from an already mentioned set. In any case, $a$ clearly favours a strong reading of the indefinite object, be it D-linked or partitive, or specific in any other sense, while its absence in (16b) is associated with a weak or existential reading. What is at stake here as well as in (17), as several authors had already noted, is the emphasis on the individualization of the referent triggered by $a$, compared to the emphasis on quantity or descriptive content that predominates in unmarked objects. So, when $a$ appears, the relevant features are the independent, autonomous reference of the object DP, and its discourse prominence. As for (17a), Laca (1987) points out that the emphasis on individuation of

9. The contrasts in (16) and (19) are taken from Brugè (2000), and the one in (17) from Laca (1987). 
the referent creates an expectation for additional information about it, thus presenting a specific tiger as a possible discourse topic; on the contrary, in (17b) there is simply a «tiger-killing» event. The theoretical distinction we need to capture the subtle semantic contrasts in (16) and (17) is strong/weak, and in both examples we are dealing with specificity in some sense.

In (18), on the other hand, $a$ is used to distinguish one interpretation equivalent to She was portraying a child from another equivalent to She was drawing a child. A very similar contrast obtains in Describió (a) una chica de ojos castaños («(S)he described a girl with brown eyes»). The problem had been already studied in Fauconnier (1984) as part of an analysis of referential ambiguities based on the notion of mental spaces. In a few words, the difference between (18a) and (18b) is related to the world where the child exists: the real world, in the $a$ version, and the world of the drawing, in the non- $a$ version. The natural way to interpret (18a) is to assume that the speaker is referring to a particular child; in (18b), the hearer/reader resorts to a different interpretation in which an event of «child-drawing» is being reported. This can be related to the individualization contrasts in the previous examples. Notice that only in (18b) is dibujar ('draw') a real verb of creation $^{10}$.

The facts I really want to draw attention to, to my knowledge first mentioned in Brugè (2000:272), have to do with the interaction between $a$ and an adverbial quantifier like siempre ('always'), as in (19). The contrast involves the obligatory/optional presence of $a$, and the crucial factor to account for it is the status of the temporal subordinate clause introduced by cuando ('when'). In (19a), the temporal clause indicates that the interpretation of un chico ('a boy') must be generic, given that a) ser guapo ('to be handsome') is an individual-level predicate and denotes a defining property, b) an indefinite subject with an individual-level predicate is typically generic, and c) the null subject of the temporal clause takes $u n$ chico as its antecedent. The essential condition for the generic interpretation of an indefinite DP is to be a topic, i.e. to be projected in the restrictive clause in the logical form of the sentence (Cohen \& Erteschik-Shir 2002); if such a condition is not met, an indefinite in a generic context is likely to be interpreted as non-specific, and not as generic. The interesting question with respect to (19a) is why should $a$ be obligatory: at first sight it may seem surprising, because contratar ('hire') is one of those verbs that do not require the obligatory insertion of $a$, and

10. As pointed out by one of the reviewers, a revision of Diesing's (1992:§4.4.5) discussion of verbs of creation could be relevant for the contrast in (18). In fact, the characteristic properties of verbs of creation like write, paint or draw (weak existential readings of their indefinite objects, impossibility of object scrambling in German, extractability from their objects) correspond to their use with unmarked objects in Spanish. If $a$ is inserted, a significant change takes place. For instance, the habitual context with adverbs of quantification used by Diesing (1992:111) as a test shows an interesting contrast: without $a$, only an existential reading of the object is available, but if the object is marked, a specific reading is possible, which, according to Diesing, is not expected with verbs of creation, as they do not permit the mapping of the object into the restrictive clause:

Habitualmente dibuja \{una niña/a una niña .

Usually he-draws $\{$ a child / to a child $\}$. 
the indefinite DP cannot plausibly receive a specific reading. The key to this puzzle is the generic interpretation of un chico: briefly, $a$ is required for the generic interpretation to arise. Its semantic contribution lies in its role as a trigger for the mapping of the object into the restrictive clause in the logical structure. The preposition is thus indirectly constraining the specification of the value assigned to the discourse referent.

As for (19b), where the temporal clause introduces an episodic predicate (irse de viaje) and its null subject takes Pilar - and not the object - as its antecedent, no generic interpretation arises in the indefinite object una canguro ('a babysitter'). The absence of $a$ correlates with a weak reading of the indefinite, while its presence is compatible with both strong (specific) and weak readings. Once the necessity to license a generic reading in the object disappears, the prepositional marker is again optional, as in (16) or (17). The relevance of the contrast in (19) lies in the fact that in (19a) $a$ has to be inserted in order to get a generic reading of the object - not a specific one-. Moreover, this is a systematic fact that can also be observed in the following examples (built on the small group of verbs that allow the two options, $a / \varnothing$, with animate objects):

(20) a. La junta escoge *(a) un conferenciante extranjero si es de The board chooses *(to) a speaker foreign if he-is of reconocido prestigio. recognized prestige.

'The board chooses a foreign invited speaker if he is really prestigious.'

b. La junta escoge (a) un conferenciante si el congreso The board chooses (to) a speaker if the conference se celebra en Madrid. is-held in Madrid.

'The board chooses a speaker if the conference is held in Madrid.'

(21) a. Sólo admitimos *(a) un profesor nuevo cuando tiene el Only we-accept $*$ (to) a teacher new when he-has the título superior.

degree.

'We only accept a new teacher when he has a degree.'

b. Sólo admitimos (a) un profesor cuando hay una plaza Only we-accept (to) a teacher when there-is a position vacante.

vacant.

'We only accept a teacher when there is a vacant position.'

Again, if the sentential context forces the generic reading of the object, as in (20a) and (21a), $a$ becomes obligatory, while it remains optional when the object is non-specific, as in the most natural reading in (20b) and (21b); a generic reading of the object with $a$ is not excluded, in any case, in (20b) and (21b). The point is that, whatever our favourite interpretations for the examples may be, if the object is 
generic it requires the presence of the case-marker ${ }^{11}$ in order to be mapped into the restriction on generic quantification. Thus, we have an additional problem that a characterization of $a$ as a specificity marker cannot solve. An account is needed both of the particular facts in (19)-(21) and of the rest of interpretive mechanisms that the preposition triggers in indefinite objects, illustrated in (16)-(18). As mentioned before, a more abstract and general notion than specificity must underlie all these interpretive effects. On the one hand, $a$ is associated with strong readings of indefinites, be they specific or generic, but not in a completely systematic way, because it admits weak readings as well. We can now make the following generalisation: $a$ is a prerequisite for strong readings, although it does not exclude weak ones. On the other hand, the linguistic content attributed to $a$ must be compatible with facts such as the licensing of bare plurals, the licensing of secondary predication, and the discourse prominence of the object, both in specific and in generic interpretations. The natural way to capture all these facts under a single account is to assume that $a$ is a topic marker, and that so-called specificity effects are inferentially derived from the meaning of the preposition. In particular, this seems the only way to reconcile specificity effects with «genericity effects» such as those in (19)-(21), given that specific and generic are varieties of strong interpretations for indefinites, and both are favoured by topic positions. This account of the semantics of object marking could be easily extended to most other cases of Differential Object Marking in the languages of the world ${ }^{12}$.

A look at the syntactic literature on object marking and object agreement shows that, when trying to express the properties of marked objects in configurational terms, a widely accepted hypothesis is locating them in a higher structural position than the basic one by means of Object Raising or some similar formal device ${ }^{13}$. This seems to me just another way to give expression to the same intuition I am dealing with here: object marking and object agreement are mechanisms that speakers use to emphasize the discourse prominence of certain arguments. In what follows I intend to remain neutral with respect to the necessity of resorting to syntactic solutions to account for the behaviour of marked objects.

Apart from the possibility of capturing all the previous data under a single generalization, there are some other arguments worth mentioning that favour an approach based on topicality. I will devote the next section to them.

11. Moreno and Pérez (2001) demonstrate that information structure can force generic interpretations even in bare plurals in Spanish, in sentences like Correos admite giros urgentes hasta las ocho ('The post office admits urgent giros until eight o'clock'): the crucial factor is the processing of the bare plural as topic or part of the background. What $a$ triggers in examples like (19)-(21) is exactly this: the mapping of the indefinite onto the restrictive clause in logical form. There is a close parallelism between the two sets of data.

12. Shokouhi and Kipka's (2003) findings about the use of the marker -râ in Persian fit in quite well, in my opinion, with my proposal about $a$ : -râ appears predominantly with expressions referring to given, accessible or identifiable entities (i.e. topical expressions), it signals that referent tracking is to be undertaken, and it combines with both specific and generic DPs.

13. See Torrego (1998) for Spanish $a$, Rapoport (1995) for Hebrew, Karimi (1990), (1996) and (1999) for Persian. 


\section{Specificity and topicality}

\subsection{Topic and referential autonomy}

So far I have tried to show that the insertion of $a$ does not consistently mark specificity in Spanish, in spite of being somehow connected to the occurrence of strong interpretations in indefinite DPs, and that its contribution to sentential meaning may reasonably be conceived of as a sort of topicality marking. In the remaining part of the paper I intend to support this perspective by collecting a variety of arguments, some empirical, some theoretical. The arguments are, briefly, the following ones. First, it is crucial to bear in mind that topicality plays a decisive role not only in the interpretive properties of indefinite objects, but, even in a more evident way, in the interpretive properties of indefinite subjects; it seems therefore natural to rely on topicality for a unified account of indefinites. Second, the whole picture emerging from the data is compatible with Van Geenhoven's theory of indefinite interpretation (Van Geenhoven 1998), which allows us to integrate the role of information structure into an elegant general framework that seems to work successfully in different languages. Third, topicality seems to be the natural connection between object marking and other grammatical mechanisms that involve animacy and referentiality/definiteness, like clitic doubling and object scrambling. A comparison with Germanic scrambling raises interesting issues. In the following sections I will elaborate on these points and comment on some difficulties surrounding the notion of topic.

Before discussing such issues, it is convenient to return to the essential connection between topicality and specificity to give a more precise picture of it. Indefinite DPs in topical positions tend to receive strong readings - generic or specific-: there seems to be no disagreement on this generalization. The most frequently discussed case is the one that involves subjects of individual-level predicates. I assume that this is to be accounted for by means of the interplay of semantic and pragmatic principles ${ }^{14}$. No obligatory or conventional link exists between specific DPs and topics, given that specific readings may arise in non-topical positions as well. The basic idea is rather that topicality forces or favours strong readings. It can be sketched informally as follows. The variety of interpretations for indefinites stems from their sensitivity to sentential contexts, and from the role of different syntactic and semantic factors in constraining the assignment of a value to the discourse referent that indefinites introduce. Indefinites, in their weak reading, establish the cardinality of the intersection of the set denoted by their restrictor and the set denoted by the predicate. Their existential properties come from an external source (the verb, or the sentential context). This makes them non autonomous expressions from a referential point of view; therefore, weak indefinites are not good topics, in general. The notion of topic is relevant here because being a topic constrains the choice of value for indefinites. If topics require referentially autonomous DPs, then topics require indefinites to be assigned some kind of strong 
reading (i.e. an interpretation where a value for a discourse referent is established independently of the cardinality of other denotations). In order to build a strong reading, speakers resort to different procedures that turn the indefinite DP into a referentially autonomous expression (by establishing previously mentioned sets of entities to obtain a partitive reading, or accommodating some contextual assumption on the existence of a particular entity being referred to).

The contribution of $a$, then, is the encoding of an instruction to process the object DP as an internal topic, that is, as a prominent and referentially autonomous argument. As $a$ is a functional head (Brugè 2000), and thus a procedural element in Sperber and Wilson's terms ${ }^{15}$, its semantic content can be considered as a procedure that must be strictly obeyed in the interpretive process: $a$ guides and constrains the inferential phase of comprehension that maps logical forms into explicatures. The occurrence of specific or generic interpretations is triggered by the necessity to obey the instruction encoded by $a$. Thus, when $a$ is not obligatory, it favours a strong interpretation of indefinite objects as a result of the inferential processes activated by its procedural nature as topic marker.

\subsection{Subjects and objects}

Topicality is responsible for the availability of different kinds of interpretations of indefinite subjects. As Milsark (1977) already pointed out, specific readings of indefinite subjects arise both with individual-level (IL) and stage-level (SL) predicates, but non-specific readings are incompatible with IL predicates, while generic ones are usually favoured by them. Recent research on this issue has tried to reduce the distribution of readings to basic distinctions in information structure (Ladusaw 1994, Jäger 1995a and 2001, Cohen and Erteschik-Shir 2002): IL predicates only give rise to categorical (bipartite) structures with topical subjects, while SL predicates may give rise to thetic structures as well. Thus, the notion of topic happens to be crucial to explain the occurrence of non-specific readings (typically unavailable in topics), generic readings (typically associated with topic constituents) and specific readings (favoured in topics, but not excluded at all in other positions). It would be very surprising if its role in the interpretation of indefinite subjects and the role it may play in the interpretation of indefinite objects were not related. Given this, a unified approach that tries to derive the behaviour of indefinite subjects and the behaviour of indefinite objects from the same underlying notion is clearly preferable to another one that resorts to different criteria for the two cases.

In fact, this argument is reminiscent of the arguments put forth in Aissen (2003) for an analysis of split ergativity patterns as an instance of Differential Subject Marking (DSM), the mirror image of DOM in the subject domain. By means of the operation of harmonic alignment, Aissen establishes constraints that express the relative markedness of various DP types in the object function as well as in the subject

15. I am assuming here that functional categories always have procedural content, unlike lexical categories, that can be conceptual or procedural (see Escandell-Vidal and Leonetti 2000). 
function, and predicts «...that there should be case-marking systems in which some subjects are marked, but not all and [...] that the factors that favour differential subject marking (DSM) will be the mirror image of those that favour DOM.» (Aissen 2003: 473)

Once the connection between DOM and DSM is established in this way, it seems just a natural extension to draw a further connection between the referential properties of marked objects and those of unmarked subjects. The class of expressions that count as marked objects (i.e. animate, referential, definite) is the class of expressions that typically occur as unmarked subjects. And the type of subject that is most likely to be marked in DSM systems (i.e. inanimate, non referential, indefinite) is the same type of subject that is most likely to be penalized by grammatical or interpretive constraints in other systems: some languages show a tendency to exclude indefinite subjects (Arabic, Chinese), some impose bans on certain readings in certain circumstances (Spanish, English, Chamorro). This last option is currently known under the label of Property Predication Restriction (PPR): properties (individual-level predicates) may only be predicated of strong DPs. Thus, DSM, the PPR and the constraints on indefinite subjects happen to be reactions to the same kind of pressure and are controlled by the same kind of scales or hierarchies ${ }^{16}$. They represent a way to draw a borderline between unmarked and marked subjects. If this is correct, it should be taken as an argument favouring the decisive role of the notion of topic in explaining DOM patterns with indefinites. Being poor candidates for topics, indefinites (and, more specifically, indefinites on their basic weak readings) should be the worst candidates for DOM, as well as the best candidates for DSM and for being subject to constraints like the PPR.

\subsection{Semantic incorporation}

Van Geenhoven's theory of semantic incorporation is one of the most successful theoretical proposals on indefinites in recent research. In the spirit of a previous analysis in McNally (1995), she develops the idea that bare nouns and certain indefinite DPs are property-denoting expressions characterized by their inherent narrow scope. Semantic incorporation by a verb licenses this kind of predicative indefinite expressions: they are absorbed or semantically incorporated by the verb as the restriction of the verb's internal argument, and their existential properties are contributed by the governing verb. Semantically incorporated indefinites, then, do not have quantificational force of their own, as it is the verb that introduces the new discourse referent. The basic predicative meaning of indefinite expressions is their default interpretation, according to Van Geenhoven (1998).

The possibility of having a semantically incorporating indefinite essentially depends on the lexical properties of the verb. Some verbs are semantically incorporating (the core cases are existential predicates), some are nonincorporating

16. As a reviewer pointed out, there is an important difference between DOM and DSM, in Spanish and possibly in many other languages: only DOM seems sensitive to animacy. 
(the core cases are individual-level predicates), and finally some may or may not be incorporating. The three classes are illustrated in the following Spanish examples, where bare plurals seem to be licensed only as objects of incorporating verbs: in (22) the existential tener allows a bare plural as its object, but rejects a definite DP, giving rise to the well known definiteness effect (see 2.1); in (23) adorar ('love'), as an individual-level transitive verb, prevents the occurrence of a bare plural, while accepting a definite DP; and finally in (24) enterrar ('bury') admits both options.

(22) Tiene grandes ventanas / *Tiene las grandes ventanas It-has large windows / *It-has the large windows

(23) Adora las patatas fritas / *Adora patatas fritas (S)he-loves the potatoes fried / (S)he-loves potatoes fried 'She loves fried potatoes'

(24) Entierra huesos / Entierra los huesos He-buries bones / He-buries the bones

In fact semantic incorporation seems to be the crucial factor in the distribution of Spanish bare plurals. McNally's (1995) and Van Geenhoven's (1998) theories are able to explain their main properties (narrow scope, lack of anaphoric readings, lack of partitive readings, discourse transparency) by means of such a notion. Moreover, they extend their approach to non-specific indefinites and opaque contexts in Van Geenhoven and McNally (forthcoming). Although there are alternative ways to develop a theory of semantic incorporation ${ }^{17}$, such a framework is undoubtedly a promising approach to the interpretation of indefinite expressions crosslinguistically. It should prove a useful tool also for the analysis of indefinite objects in languages that exhibit DOM systems. In fact the expectations begin to get confirmed as soon as the existential contexts exemplified in (4)-(5) are taken into account. According to McNally and Van Geenhoven, definiteness effects in these contexts are due to the incorporating nature of the predicate and the resulting weak interpretation of indefinites. The exclusion of $a$ after haber and tener in the standard existential construction follows naturally from the ban that DOM imposes on semantic incorporation ${ }^{18}$. The ungrammaticalities in (4)-(5) result from the clash between the incorporating verb and the anti-incorporating properties of the prepositional

17. Different developments of the notion of semantic incorporation can be found in Chung and Ladusaw (2004), Farkas and de Swart (2003a) and (2003b).

18. It is worth pointing out that the behaviour of existential predicates and the group of incorporating verbs I am considering here is cross-linguistically homogeneous in its rejection of all the devices associated with specificity and object prominence: the same as Spanish haber rejects $a$, incorporating or «definiteness-effect verbs» in Ostyak exclude object agreement (Nikolaeva 2001: 21-22), the equivalent of have in Persian rejects the particle -râ (Karimi 1990: 174), and its equivalent in West Greenlandic is a morphologically incorporating affix (Van Geenhoven 1998: chapter 5). 
marker. In addition, there are other facts that can be covered under the same approach, as we will see now.

Although the interaction between semantic incorporation and topic-focus structure is not investigated in detail in Van Geenhoven (1998), it is not difficult to find certain correlations between them that help to illuminate certain aspects of the semantics of Spanish $a$. Assuming a) with McNally (1995) and Laca (1996), that bare plurals in Spanish are predicative expressions, and b) that they are interpreted by semantic incorporation, it follows that their syntactic distribution must be regulated by the lexical properties of the verbs and predicates that take them as arguments (as shown in (22)-(24)) and by the resistance that certain argument positions offer to incorporation processes. These positions are basically preverbal subject and $a$-marked object (leaving indirect objects aside): in a few words, sentence-internal topical positions. It is quite natural to think that an argument inside a topic position should not make a good candidate for incorporation or absorption: the more prominent an argument is, the more reluctant it is to being interpreted as a predicate modifier or as «part of the predicate». The constraints imposed by individual-level predicates on bare plurals (cf. (23)) are reducible to the topicality factor as well: as often stated in the literature, subjects of individual-level predicates are topical (cf. 3.2), and, furthermore, their objects are topical too, as Laca (1990) demonstrated in her study of Spanish bare plurals. This is one of the reasons why individual-level predicates do not give rise to thetic judgements, and is also responsible for the contrast in (23). So the general notion of topicality underlies both the diverging selection properties of verbs like tener, adorar and enterrar and the discourse properties that differentiate categorical and thetic judgements, and accounts both for the interpretations of subjects and direct objects.

The generalization that relates these facts concerning bare plurals and the previous data about DOM in Spanish is the following: internal topic positions tend to block incorporation processes. Notice that the generalization is about internal topic positions, because external topics may receive a weak reading quite naturally, as the following examples of left dislocation in Spanish (25) and split topicalization in German (26) demonstrate ${ }^{19}$ :

(25) Bueno, este verano, libros, han leído.

'Well, this summer, books they have read.'

(26) Hausaufgaben haben die Studenten nicht mal zwei gelesen. Hometasks have the students not even two read. 'As for homework sets it is not the case that the students read even two.'

19. Example (26) is from Van Geenhoven (1998: 5). Van Geenhoven takes German split topicalization as a clear instance of semantic incorporation. A sort of split topicalization is also possible in Spanish:

Ejercicios, los estudiantes no han leído ni siquiera dos.

Exercises, the students have not read even two 
The indefinite bare nouns libros ('books') in (25) and Hausaufgaben ('homework') in (26) are non-specific. This suggests that the interpretive constraints on external topics are weaker than those operating on internal topics (subjects and objects), as property-type expressions can be used as external topics, but not as internal topics ${ }^{20}$. If we assume that non-specific indefinites are interpreted via semantic incorporation à la Van Geenhoven, this operation must be available in some sense for external topics, but it seems forbidden, or at least disfavoured, in internal topics or prominent arguments. This is an issue that should be worth investigating in more detail, but I cannot even sketch an explanation for it here ${ }^{21}$. I will simply limit my speculations to internal topic positions, trying to offer some additional support for the idea that «(non)specificity» effects in subject and object positions are related to topicality. A plausible answer to the problem of the asymmetry between the two types of topical positions could be based on the intuition that we are actually dealing with two different notions of topicality: I shall address the issue briefly in section 3.5.

Once semantic incorporation has been introduced as a tool for the study of indefinite descriptions, the obvious question that comes to mind is how it is related to DOM and its effects in Spanish. The answer is obvious as well: the insertion of $a$ should have some consequence for the incorporation process, if $a$ functions as a topic marker and topical positions constrain the possible readings of indefinite descriptions ${ }^{22}$. There are some proposals in this direction in the literature. Bleam (1999a:180; 1999b:33-34) considers $a$ as an indicator of a type shifting operation on the indefinite: $a$-marked bare plurals are shifted to a kind reading or to an existential reading instead of being semantically incorporated to the verb, and indefinite DPs are shifted to a generalized quantifier status when $a$ occurs (Bleam's A-Marking Hypothesis). This seems a natural way to interpret the facts: semantic incorporation is the default interpretation procedure for unmarked indefinites, and the insertion of a special marker triggers a different interpretation procedure (accommodation, choice functions or any other mechanism for deriving specificity); the result is a variety of strong readings, while unmarked indefinite objects, as incorporated predicative expressions, get only weak readings.

However, two points should be stressed: first, accepting an analysis along these lines does not mean accepting that $a$ encodes a specific procedure of the type «Shift to generalized quantifier», which I think would be a mistaken interpretation of the facts; second, there is a residual problem with the availability of weak or non-specific readings in marked indefinites as well (as shown in (7)-(11)). Recall that $a$ may appear with non-specific DPs, especially when it is obligatory and when there

20. See Aissen (1992) for a study of the distinction between external and internal topics in Mayan.

21. A crucial factor for the acceptability of (25) and related structures is the absence of a clitic in a sentence-internal position. As for specificity effects, a parallelism between internal and external topic positions can be invoked only when there is such a clitic (i.e. in clitic left dislocation structures).

22. Recall that the expected consequences will only be visible in those contexts where the insertion of $a$ is fully significant. 
is no specific reading contextually available: this is an indicator of how far the expansion of DOM has gone in modern Spanish and how much it distorts the relationship between $a$ and specificity. One must conclude that nowadays $a$ cannot be said to block semantic incorporation systematically. The only safe generalization is that the absence of the preposition marks incorporation. In the central cases where $a$ and $\varnothing$ freely alternate, $a$ represents a non-incorporated reading and $\varnothing$ an incorporated one. Thus, a link between DOM and the impossibility of semantic incorporation must still survive, with topicality, again, underlying such a link.

An additional argument in favour of such a link, and one that has gone unnoticed, as far as I know, is the fact that in Spanish the group of psychological verbs that require $a$ in their objects (which are all individual-level predicates) correlates quite closely with the group of verbs that reject bare plurals as objects (an expected behaviour in individual-level predicates). As the correlation does not seem to be arbitrary, the most straightforward account is one that characterizes those verbs as non-incorporating; incorporating verbs are expected to accept bare plurals as well as unmarked objects. The relevant facts are represented in the grammaticality patterns in (27) and (28), where non-incorporating verbs are compared to a small group of typically incorporating verbs ${ }^{23}$ :

(27) a. \{odiar/ admirar/ despreciar/ amar/ aborrecer/ soportar $\} *(a)$ una persona 'to hate/ admire/ despise/ love/ detest/ put up with... a person'

b. $\{$ llevar/ curar/ contratar/ describir/ encontrar/ver $\}$ (a) una persona 'to take/ cure/ hire/ describe/ find/ see a person'

(28) a. $\left\{*_{\text {odiar }}\right.$ *admirar/ *despreciar/*amar/*aborrecer/*soportar $\}$ personas 'to hate/ admire/ despise/ love/ detest/ put up with persons'

b. \{llevar/ curar/ contratar/ describir/ encontrar/ ver $\}$ personas 'to take/ cure/ hire/ describe/ find/ see persons'

Therefore, bringing semantic incorporation into an account of Spanish DOM, we obtain some benefits, both at the descriptive and the theoretical level: 1) the distribution of unmodified bare plurals is reduced to a simple mechanism, controlled by a variety of lexical and syntactic factors; 2) the same mechanism is responsible for the readings of subject and object indefinites, in languages with explicit DOM systems and in languages that do not mark semantic incorporation explicitly; 3) the insertion of $a$ fits into a general theory of indefinite descriptions and its connection with topicality is preserved.

23. The two paradigms in (26) and (27) cannot be taken as representative of the remaining verbs without paying attention to the bundle of overlapping factors that control the insertion of $a$. In fact, things become much more complicated as soon as other groups of verbs are examined. In any case, the basic correlation presented here reinforces the idea that, in spite of the expansion of DOM in modern Spanish, there are still areas where the link between the $a / \varnothing$ alternation and semantic incorporation can be clearly perceived. 


\subsection{Clitic doubling and scrambling}

It is well known that clitic doubling and object scrambling are among the grammatical phenomena that usually interact with definiteness and specificity ${ }^{24}$. One could wonder what the origin of such an interaction is. Indeed that is the right question to pose if one is looking for a principled account of the behaviour of $a$ in Spanish, because a look at the similarities among all these grammatical devices yields a number of interesting results for the study of DOM. In this section I examine the way in which the occurrence of $a$ is related to clitic doubling and scrambling, in order to find out what lies behind the three constructions. And the unifying notion will be, unsurprisingly, the marking of internal topics.

At least since Richard Kayne proposed what has been known as «Kayne's generalization» (Clitic doubling requires the object to be case-marked), clitic doubling and DOM have been considered as related syntactic mechanisms. In Spanish in fact direct object doubling seems to depend on the insertion of $a$ before the object $\mathrm{DP}^{25}$. The two grammatical processes are triggered by the same kind of features: animate and referential/definite/specific. Nevertheless in standard modern Spanish the conditions for direct object doubling are more restrictive than the conditions for object marking: only personal pronouns trigger doubling, while any kind of animate and definite/specific DPs activate the insertion of $a$ (a significant difference is that negative quantifiers cannot be clitic doubled, but can be $a$-marked). As Bleam (1999a: 199) correctly points out, «the semantic properties which give rise to clitic doubling form a subset of the semantic properties which give rise to the prepositional accusative...». In some varieties of Spanish, like those spoken in Río de la Plata (Argentina) and the Basque Country ${ }^{26}$, clitic doubling is governed by less restrictive conditions and extends to definite and specific indefinite DPs, but it still obtains in a subset of the cases where $a$-marking obtains. This kind of dialect variation cannot disguise the fundamental similarity of the two phenomena. Both are expanding along the same scales and hierarchies. Moreover, it is precisely in some of the non-standard varieties that the parallelism emerges strikingly. Franco and Mejías-Bikandi (1999) show that in Basque Country Spanish the condition for an indefinite object to be clitic-doubled is to receive a strong interpretation: in (29a) there is only a strong (presuppositional, in Franco and Mejías-Bikandi's terms) interpretation, imposed by clitic doubling, while in (29b), where the object is not doubled, the indefinite DP is ambiguous between a strong and a weak interpretation (notice that $a$ is present in both cases).

24. See Lyons (1999: chapter 5) for a survey and for general considerations on the nature of the phenomena. This section owes much to Alexiadou and Anagnostopoulou (1997), Gierling (1997), Delfitto and Corver (1998), Bleam (1999a), Meinunger (2000) and Nikolaeva (2001).

25. Detailed analyses and discussions are provided by Torrego $(1998,1999)$ and Bleam $(1999 a, 1999 b)$.

26. See Suñer (1988) and Franco and Mejías-Bikandi (1999) for a study on clitic doubling and specificity in these varieties of Spanish. A tighter correlation between clitic doubling and object marking can be observed in Romanian (see Farkas and von Heusinger 2003). 
(29) a. Le he visto a un marinero.

To-him I-have seen to a sailor.

b. He visto a un marinero.

I-have seen to a sailor.

'I have seen a sailor.'

The subtle contrast in (29) confirms that explicit object morphology —clitic doubling is an instance of object agreement - usually forces strong interpretations in indefinites. Bleam (1999a: 44-55) obtains the same results in her analysis of Leísta Spanish (a variety that resorts to the dative clitic le for animate direct objects, and for doubling), Alexiadou and Anagnostopoulou (1997) report similar interpretive effects in Greek, and Nikolaeva (2001) describes how object agreement is associated with strong interpretations in Ostyak, an Uralic language spoken in Western Siberia (and the correlation between object agreement and specificity is well attested in many other languages).

Given that clitic doubling (or object agreement) and $a$-marking display several common properties (they are triggered by the same features, they are both optional -in the cases we are interested in-, they have similar effects), it is reasonable to ask whether some abstract and general property might not be at the origin of such parallelisms. Some authors have tried to give an answer in terms of formal or configurational analogies, usually related to some kind of movement of the object to higher nodes in the syntax. I do not intend to go into a critical analysis of such proposals, but my impression is that the particular interpretive properties of the constructions are simply stipulated in them, rather than accounted for ${ }^{27}$. A number of problems still have to be faced by these accounts: Where do specificity effects come from? Why would certain functional heads be associated with strong readings? Why does animacy correlate with specificity? Why is it direct objects that typically show the aforementioned common properties? In a few words, the way syntax is related to semantics (and pragmatics) needs a more principled explanation.

On the other hand, starting from the assumption - which I find quite natural - that human languages often resort to different types of object marking or object agreement to indicate a high degree of discourse prominence in direct objects (i.e. in arguments that typically tend to be less prominent than subjects or indirect objects), the facts can be accommodated into a coherent picture that highlights the role of topicality - again — and its associated interpretive properties. But, before trying to sketch such a picture, it is convenient to bring scrambling or object shift into the scene.

The extensive literature on scrambling ${ }^{28}$, particularly in Germanic languages, has convincingly shown that it is systematically associated with strong readings

27. Meinunger's (2000) theory of Agreement nodes as topic hosts is an exception, in that it combines movement to functional nodes and the derivation of all the interpretive effects from the topical status of such nodes.

28. I rely on the data presented in Diesing (1992), Delfitto and Corver (1998), Neeleman and Reinhart (1998), Choi (1999), Meinunger (2000) and Karimi (ed.)(2003). 
of indefinites (both generic and specific/referential), and, in addition, that it can have parallel consequences in the interpretation of definites (an issue I do not intend to discuss here ${ }^{29}$ ). I reproduce in (30) a representative contrast in German (from Meinunger 2000: 66):

(30) a. sie weil bestimmt schonmal eine Sinfonie gehört hat she since surely already a symphony heard has

b. weil sie eine Sinfonie bestimmt schonmal gehört hat since she a symphony surely already heard has 'since she surely has already heard a symphony'

While in (30a) the indefinite object eine Sinfonie is inside the VP, in its base position, and it only gets a weak existential reading, in (30b) it is outside the VP boundary and gets a strong reading. Scrambling shares a number of properties with clitic doubling, as argued by Alexiadou and Anagnostopoulou (1997:144-153), and, what is more important here, with object case-marking in Spanish and other languages: apart from the well known definiteness/specificity constraints, there are interesting properties related to binding and scope, obviously not independent from the aforementioned constraints. Scrambling and clitic doubling may increase the discourse prominence of direct objects with respect to indirect objects, and so does case-marking. The following examples involve ditransitive verbs and illustrate binding/scope asymmetries stemming from the presence or absence of $a$ : the contrast in (31) shows how case-marking of the direct object can turn it into a prominent binder for a pronoun inside the indirect object; those in (32) and (33) show how case-marking favours wide scope readings of the direct object with respect to the indirect object.

(31) a. Devolvieron un prisionero a su tribu. They-returned a prisoner to his tribe.

b. Devolvieron a un prisionero a su tribu. They-returned to a prisoner to his tribe.

(32) a. Devolvieron un prisionero a cada tribu. They-returned a prisoner to each tribe.

b. ??Devolvieron a un prisionero a cada tribu. They-returned to a prisoner to each tribe.

(33) a. Enviamos un especialista a todos los departamentos afectados. We-sent an expert to all the departments affected.

b. Enviamos a un especialista a todos los departamentos afectados. We-sent to an expert to all the departments affected. 
All the differences between $a$ and $\varnothing$ arise from the prominence the indefinite object acquires when case-marked. As for the examples in (31), $\varnothing$ favours the reading where the object un prisionero is not the antecedent of the possessive $s u$, and yet $a$ imposes the opposite reading, with un prisionero as the antecedent of the possessive. In a strictly configurational approach, this seems to be the result of the raising of the object to some higher node (i.e. the counterpart of scrambling in a language without scrambling like Spanish), but one does not need to postulate a raising rule triggered by $a$, if it is assumed that $a$ marks an internal topic, thus turning the indefinite object into a prominent antecedent for an anaphoric pronoun. In any case, the parallelism between case-marking, scrambling and clitic doubling is descriptively clear in the binding facts. I believe that it holds for scope facts such as those shown in (32)-(33) too.

In (32) the contrast is particularly robust. The distributive quantifier cada in the indirect object forces a distributive reading in the indefinite object; such a reading is acceptable in the first case, without $a$, but unacceptable in the second one, with $a$. Again, the prominence of the $a$-marked object is responsible for the difference: it follows from the raising of the object to a position where it can no longer be bound by the quantifier — on a configurational approach-, or, alternatively, from the fact that DPs in topic positions are rarely inside the scope of any quantifier - on an account in terms of topicality. Therefore, the oddity of (32b) is the result of a clash between the inherently distributive nature of cada and the effects of $a$-marking.

Finally, (33) involves the scope interaction between the indefinite object un especialista and the quantified indirect object todos los departamentos. As expected, the indefinite DP has wide scope when it is preceded by $a$, as in (33b) (where a unique expert is supposed to have been sent to every department), and narrow scope when it is not case-marked, as in (33a), where a different expert has been sent to each department.

The facts in (32)-(33) are strikingly similar to the well known «scope-freezing effects» that arise in English or Japanese when the indirect object precedes the direct object in examples like those in (34), from Nakanishi (2002: 141):

(34) a. The teacher assigned one student every problem.

b. John-ga [sannin-no onna]-ni [futari-no otoko]-o syookaisita. John-NOM [three-GEN woman]-DAT [two-GEN man]-ACC introduced 'John introduced to three women two men.'

In (34) the Indirect Object - Direct Object order blocks one of the readings available in the opposite order, Direct Object - Indirect Object, leaving as the only possibility the surface scope reading $(\mathrm{IO}>\mathrm{DO})$. The preposing of indirect objects in ditransitive constructions, thus, has a «scope freezing effect», which, according to Nakanishi (2002), cannot be due to general properties of movement rules, but rather is due to the specificity of the indirect object in IO-DO order, which she takes in such contexts to denote a choice function. Her analysis brilliantly covers several facts in the interpretation of ditransitive structures, and is compatible with 
the idea that the specificity responsible for «scope freezing» derives from the topical status of the indirect object in IO-DO order. This is relevant for an analysis of $a$-marking because it reinforces the parallelism between DOM and the variety of object shift rules operating in natural languages, as well as the central role of topicality in the distribution of the interpretations for indefinite descriptions. In fact the null hypothesis should be that we have «frozen scope» both in dative shift and in object case-marking because the two constructions encode the same kind of procedure: an indication to process a constituent as an internal topic (this is the basic meaning of scrambling in Germanic languages, according to the recent literature ${ }^{30}$ ).

Building partially on Meinunger's (2000) claims about the topic/agreement connection and the way it relates to scrambling, I would like to sum up by stating that an analysis of DOM in Spanish cannot ignore the analogies that relate it to all the other devices that trigger strong interpretations in direct objects. $A$-marking in Spanish bears evident resemblances with grammatical mechanisms such as a) morphologically different cases for objects or special particles (accusative/partitive in Finnish, accusative/genitive in Russian, accusative/absolutive in Turkish, -râ in Persian), b) object agreement (Hindi, Hungarian, Bantu languages, Macedonian, Ostyak), and c) scrambling or object shift (German, Dutch, Korean, the ba-construction in Chinese). All three phenomena (case-marking, agreement, positional differences) have essentially the same interpretive consequences, and the natural way to integrate them all in a coherent explanation is assuming that they behave as topic markers, and that the higher a constituent is in the animacy and definiteness/specificity scales, the better it fits in a topic position. Moreover, this seems the only way to account for the role of animacy in the aforementioned mechanisms, bearing in mind that there is a natural correlation between being a topic and referring to an animate entity ${ }^{31}$. Finally, this also seems the only simple way to integrate the representation of specificity constraints on subjects and objects into the same picture. What remains to be discussed is why different languages choose different «cutoff» points along the scales of animacy and definiteness/specificity, and why some languages extend the range of case-marking or agreement to the end of the scales, thus making no distinction between prominent and non-prominent arguments (see Meinunger 2000: 177-178). Answers to such questions are not easy to find.

\subsection{Some problems}

As we have seen in the previous section, there is enough supporting evidence linking the analysis of $a$-marking (and DOM in general) to topicality, and this deserves

30. Neeleman and Reinhart (1998) rely on destressing and discourse-linking to account for the basic property of scrambling, Delfitto and Corver (1998) take familiarity as the key feature, Choi (1999) uses a general notion of prominence that covers both topic and contrastive focus, and Meinunger (2000) relates scrambling to topics, in the sense of constituents that bear familiar information and act as anchors for the new information to be linked to the old information. Although these approaches are not equivalent, I assume that all of them point to some aspect of what it means to be a topic.

31. For the interaction between topicality and animacy, see Dahl and Fraurud (1996), Yamamoto (1999) and Farkas and von Heusinger (2003). 
serious consideration. Nevertheless, there is still an obvious difficulty: the analysis is based on a notoriously vague and elusive notion. The term topic probably covers several slightly different constructions resulting from the combination of more basic semantic dimensions; according to some authors, there is no unitary notion underlying all topic-comment constructions in natural languages ${ }^{32}$. As already pointed out in section 3.3, the distinction internal topic/external topic needs to be investigated carefully if we want to have a more precise notion of topic. But even dealing exclusively with internal topics, a need emerges for an accurate specification of the way the term is used.

In the preceding sections I have been using topic basically as an information structure concept, in the sense of «anchor for new assertions» and «referentially autonomous expression», typically — but not necessarily— conveying given information. If my approach is correct, case-marked objects in Spanish should share most of their properties with similar cases of internal or secondary topic marking in other languages. Nikolaeva (2001) provides us with a very interesting example of a language, Ostyak, where object agreement marks secondary topics. A comparison with Spanish can help to understand the nature of the problems surrounding the concept of topicality. Nikolaeva (2001: 26) defines a secondary topic as «an entity such that the utterance is construed to be about the relationship between it and the primary topic». Secondary topics tend to be encoded cross-linguistically as direct objects. In Ostyak object agreement is optional: when the object does not agree with the verb, it is interpreted as focus, but when agreement appears the object acquires certain topical properties (existential presupposition ${ }^{33}$, activation/definiteness, and the need for an explicit primary topic in the utterance ${ }^{34}$ ). These are all properties that secondary topics in Ostyak share with most cases of case-marked objects. But the fact I want to concentrate on is the incompatibility of object agreement in Ostyak with focus on the object: if the object gets narrow focus (contrastive or not), there is no agreement. Nikolaeva (2001: 29-31) shows that object agreement is thus extremely sensitive to focus structure, as one should expect if it marks secondary topic as a relation in information structure. Moreover, this is a strong argument for her analysis in terms of secondary topics. The problem for my approach to $a$-marking is that the occurrence of $a$ is not sensitive at all to focus structure: it is compatible with all kinds of focus - contrastive or informative. In other words, the Spanish-Ostyak parallelism fails because DOM in Spanish is not motivated solely by information structure, whereas object agreement in Ostyak is, according to Nikolaeva (2001). The same problem arises in a comparison of Spanish

32. Jacobs (2001) shows that different topic-comment constructions in German (categorical sentences, left dislocation, hanging topic left dislocation, free topic, I-topicalization) are characterized by different combinations of four basic attributes: informational separation, predication, addressation, and frame-setting.

33. This is relevant for a comparison with Spanish $a$, as one of the basic constraints on object agreement in Ostyak has to do with specificity: non-specific expressions never trigger agreement (Nikolaeva 2001: 20-21).

34. Here we have another parallelism with Spanish $a$, since it also occurs predominantly in sentences with agentive and topical subjects (i.e. prototypical external arguments). 
$a$ and Germanic scrambling, in spite of the similarities mentioned in section 3.4: scrambling is controlled by information structure factors (destressing, defocusing, familiarity...) that do not seem to play a prominent role in Spanish DOM. Maybe this is related to another difference I did not mention before - the fact that animacy is not relevant for scrambling in German or object agreement in Ostyak, but it certainly is for DOM, in Spanish as well as in many other languages.

At this point I can only offer some speculations about the possibility of integrating these problematic facts into a coherent picture. The topicality hypothesis for $a$ seems to be worth maintaining, but there is a need to reconcile the two different notions of prominence that underlie the whole array of data I collected in the previous sections.

On the one hand, I have been talking about topics as prominent constituents in information structure, i.e. as anchors for new assertions, mostly discourse-linked, and opposed to focused constituents. This is what governs German or Dutch scrambling, Ostyak object agreement, or the readings of preverbal indefinite subjects and generic indefinite objects in Spanish. Animacy is not involved in this kind of informational prominence: scrambling, for instance, does not seem to be sensitive to animacy as case-marking is.

On the other hand, I have been talking about topics as prominent arguments in event structure, in the sense that they are referentially autonomous with respect to the verb and denote direct participants in the event denoted by the predicate ${ }^{35}$. This is obviously independent of focus structure, but frequently intertwined with factors like animacy and affectedness. It is the basic feature underlying DOM, as well as many instances of clitic doubling and phenomena like semantic incorporation, case-marking and the stage/individual distinction. Furthermore, it seems to be involved in syntactic operations that are known to modify the relative prominence of certain expressions, such as dative shift and possessor raising ${ }^{36}$. In any case, it is relevant for the occurrence of specific interpretations.

Given this, one could reasonably reach the conclusion that, due to the inherent vagueness of terms like topic or topicality, I have been mixing and confusing two different notions in the analysis of $a$-marking in Spanish: more precisely, two different kinds of topicality or prominence, one pertaining to information structure or focus structure, the other related to event structure and the distinction autonomous vs incorporated. In fact, I have been relying sometimes on one sense of topical and sometimes on the other. But, even accepting that better tools are needed for a complete account of the facts, I believe that there are at least two reasons to approach the interpretive effects of DOM along these lines: first, the two

35. See Laca (1987) and Martín (1999) for remarks on this kind of prominence, and the analogy with subjects and indirect objects. It is worth pointing out that Karimi (1999: 708), in her analysis of

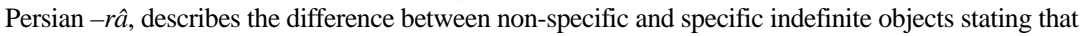
in the first case the event is the focus of attention, whereas in the second one it is instead the participants in the event. Not by chance, she uses the same words that other authors have used to describe the effects of $a$-marking in Spanish.

36. Bleam (1999a) studies how dative shift and clitic doubling share the property of presenting an entity as a direct participant in the event. 
kinds of topicality actually interact in a number of contexts (for instance, in the generic reading of $a$-marked objects, and in the strong readings of individual-level predicates ${ }^{37}$ ), so that it is not possible to keep them separated in every case; second, the price to be paid for maintaining «informative» topicality and «participant» topicality as strictly independent notions is considerable, as the specificity effects common to all the constructions considered here - as well as other common properties - can no longer be captured under a unified explanation. In other words, we would miss the main generalizations involving the place of specificity in grammatical constructions.

The way in which the two kinds of topicality/prominence interact deserves careful investigation. It might well be that some languages are globally more sensitive to one of them, and some to the other. It could be that the two are different manifestations of a more abstract notion of salience/prominence ${ }^{38}$. A plausible alternative proposal worth exploring, as suggested by one of the reviewers, could even be taking incorporation, instead of topicality, as the central notion, assuming that, when it is still optional, $a$ is a sort of «anti-incorporation» device associated to the contexts where semantic incorporation cannot take place (essentially, topic positions). At any rate, a great amount of research is still needed on the topic.

\section{Specificity in grammatical theory}

\subsection{More grammatical facts related to specificity}

Once a treatment of specificity in DOM contexts has been sketched, it should be integrated into a wider perspective on the role of specificity in grammar. In particular, something has to be added concerning other alleged specificity markers in Spanish that do not seem to be amenable to an analysis based on topicality, and on the ways through which specificity appears to be an active feature in syntactic configurations. In this section I will concentrate on these issues, before offering some concluding remarks.

Besides case-marking and clitic doubling, there are two well studied grammatical elements correlated with specificity that have to be mentioned: mood in

37. As for the generic reading, it seems to depend solely on information structure; but then, several questions arise: why is $a$-marking associated to it (if $a$ is related to prominence as participant in the event)? In the case of the constraints imposed by individual-level predicates on their arguments, why is information structure relevant if the stage/individual distinction is essentially lexical and related to event structure?

38. Very often linguists resort to quite abstract characterizations of the principles underlying the hierarchies of definiteness and specificity. When discussing the nature of such hierarchies, Lyons (1999: 215) suggests that «what we are dealing with is the subjective prominence or salience, in some sense, of entities in the domain of discourse. [...] Languages will then differ as regards what kinds of noun phrase conventionally count as prominent.» Lazard (1982) suggests that the function of the postposition $-r a ̂$ in Persian is polarizing the object in a sentence and distinguishing it from «depolarized» objects; this is another intuitive way of talking about prominence, in some sense. Unfortunately, in the present state of our knowledge, a more precise definition of prominence or salience is not easy to obtain. 
relative clauses and adjective position inside the DP (Leonetti 1999: 865-868). To insert such factors in a general framework for the study of specificity, it is necessary to bear in mind that grammar biases specific or non-specific readings of indefinites by means of three different mechanisms:

a) including a certain amount of descriptive information inside the DP structure, in noun complements and modifiers;

b) inserting modality markers either inside the DP (for instance, the subjunctive in relative clauses) or outside the DP (in verbal morphology);

c) by means of some syntactic mechanism usually external to the DP structure, such as word order, agreement or case-marking.

These three kinds of grammatical operations can be characterized as ways of constraining (or keeping unconstrained) the assignment of a value to the discourse referent associated with an indefinite DP. As is well known, accumulating expressions with a rich descriptive content inside the DP considerably reduces the possibility of having non-specific interpretations, whereas the absence of such expressions strongly favours it, by keeping open the choice among different values. Modality markers, particularly those that give rise to intensional contexts (i.e. future, imperative...), create linguistic environments where value assignments to discourse referents are only minimally constrained. Finally, the syntactic devices I have discussed in previous sections have a clearly restrictive effect on such value assignments, and lead to the assumption that the discourse referent must be salient in discourse, and thus probably specific.

There are good reasons to think that none of these grammatical operations encodes (non-)specificity in any sense. The subjunctive mood obviously does not encode it: characterizing subjunctive as expressing non-specificity would not allow us to account for its syntactic distribution and its contribution to utterance interpretation. The same could be said of any modality marker. Being some of them more or less systematically associated with certain readings of DPs does not mean that they encode such readings.

As for adjective position inside DPs, Picallo (1994) and Bosque (2001) have demonstrated that the prenominal position of epithets and elative adjectives in indefinite DPs forces the specific reading, while the postnominal position is compatible with strong and weak readings. In (35)-(36), the DPs una interesante nove$l a$ and un famoso actor must be specific; hence, a sentence like Busco un famoso actor in (36) is ungrammatical without $a$, but is grammatical when the order is $\mathrm{N}$ - Adj: Busco un actor famoso.

(35) Quiero leer \{una novela interesante / una interesante novela I-want to-read $\{\mathrm{a}$ novel interesting / an interesting novel \}

(36) a. Busco a \{un actor famoso / un famoso actor I-look-for to $\{$ an actor famous / a famous actor $\}$

b. Busco un actor famoso / *Busco un famoso actor I-look-for an actor famous / *I-look-for a famous actor 
Again there is no encoding of specificity. The contrasts have rather to do with the referential properties that epithets and elative prenominal adjectives require in the DP. The crucial fact is that they cannot be interpreted as restrictive modifiers. The only available interpretation is an explicative or appositive one. This has important consequences for the referential status of the DP, simply because explicative modifiers operate on referentially autonomous expressions, i.e. on expressions whose reference is established independently of the property denoted by the prenominal adjective. To avoid a semantic clash between the modifier and the host phrase, the whole DP is assigned a strong interpretation (a specific one, usually). I want to stress that the notion that relates this kind of facts to the other facts discussed here is referential autonomy: just the basic property of topics. In a few words, the trigger for the inferential specification of a strong reading is essentially the same for $a$-marking, clitic doubling, subject and object raising, and finally prenominal elative adjectives, which allows for a unified account of specificity effects in all these constructions.

\subsection{Does grammar encode specificity?}

All the preceding discussion leads me to advance the general hypothesis that in natural languages the grammatical system does not encode features like specificity, familiarity or referentiality, but more abstract features related to information structure and processing instructions. More precisely, I do not want to say that certain lexical items (determiners and quantifiers) cannot encode specificity; in fact we know that several languages have determiners or quantifiers that are systematically associated with specific readings. What I want to suggest, contrary to Delfitto and Corver (1998) and Karimi (1996), among others, is that functional categories external to DPs (i.e., agreement, case, focus, and so on, leaving aside tense and other deictic categories) - the categories responsible for word order phenomena and basic constructions in natural languages - do not encode specificity. Semantic and pragmatic notions like specificity, familiarity, rigid designation or discourselinking do not seem to play any role in the computational system. This idea is not new, at least for DOM and related phenomena. It takes up Neeleman and Reinhart's (1998: 346) conclusions about scrambling and its relationship to specificity and D-linking: «There is, then, no reason to assume that these discourse options are coded in any way in the computational system.» The proposal is also in the spirit of Meinunger's (2000) work on scrambling, topicality and agreement nodes: in his analysis it is the topic status of an argument, and not specificity or definiteness, that activates agreement projections.

I cannot develop a complete discussion of the general issue here. Nevertheless, I would like to mention that one of the reasons why proposals like this must be studied and evaluated is that we need to constrain the possible range of meanings that functional nodes are able to code. We need to make progress in that direction to understand what kind of meanings syntax can express, and it is reasonable to think that it should be a highly restricted series of meanings. We need to put restrictions on the features associated with functional nodes in order to strengthen syntactic 
theory and limit the proliferation of new categories that sometimes may not be sufficiently justified. The price to be paid for carrying out this operation is, at least for the moment, the subsuming of specificity under a vague notion of prominenceltopicality ${ }^{39}$, but some progress has been made in the specification of what is encoded by the grammatical system and what is pragmatically inferred.

To sum up, the central idea I have been arguing for is that Spanish has no grammatical device that encodes specificity; the devices that grammars usually describe ( $a+$ direct object, mood in the relative clause, adjective position, syntactic position of the DP) encode other meanings, mostly related to information structure, modality and the prominence of arguments. Specificity is pragmatically inferred on the basis of the procedural semantics of such devices and information taken from sentential context and communicative situation. The inferential process is one of the fundamental tasks in the determination of explicatures: reference assignment to DPs and other referential expressions. In this sense, accessing a specific reading is just a way to obey the instructions encoded by certain elements and developing an incomplete logical form into a complete explicature. Specificity appears to be an epiphenomenon, the indirect result of the interaction of several different factors. So too are features like affectedness or discourselinking.

If this idea is extended to the analysis of other languages, it leads us to the general hypothesis that syntax does not encode features like [specificity] or [familiarity] in functional nodes; as a consequence, phenomena like scrambling, differential object marking, clitic doubling, agreement and so on are triggered by other kinds of features. The immediate advantage I seek to obtain is a better understanding of the distinction between those aspects of utterance interpretation that are semantically encoded in the logical form and those aspects that are pragmatically inferred. On the other hand, the main difficulty is posited by the necessity of 1) defining the abstract linguistic meaning of different syntactic positions and operations, and 2) mapping such a meaning into full fledged explicatures by means of pragmatic principles. Much research remains to be done on these issues.

\section{References}

Abbott, Barbara (1995). «Some Remarks on Specificity». Linguistic Inquiry 26: 341-347. Adger, David (1996). «Economy and Optionality: Interpretations of Subjects in Italian». Probus 8: 117-135.

Aissen, Judith (1992). «Topic and Focus in Mayan». Language 68: 43-80.

Aissen, Judith (2003). «Differential Object Marking: Iconicity vs Economy». Natural Language and Linguistic Theory 21: 435-483.

Alexiadou, Artemis; Anagnostopoulou, Elena (1997). «Toward a Uniform Account of Scrambling and Clitic Doubling». In: Abraham, Werner; Van Gelderen, Elly

39. See Lyons (1999: 226) for the same conclusion on certain aspects of definiteness marking, and Farkas and von Heusinger (2003) for an attempt to deconstruct a notion like prominence in a series of parameters. 
(eds.). German: Syntactic Problems, Problematic Syntax?. Tübingen: Max Niemeyer, pp. 143-161.

Bleam, Tonia (1999a). Leísta Spanish and the Syntax of Clitic Doubling. University of Delaware, doctoral dissertation.

Bleam, Tonia (1999b). «Object Bare Plurals in Spanish and the Semantics of Personal A». In: Authier, Jean-Marc; Bullock, Barbara; Reed, Lisa (eds.). Formal Perspectives on Romance Linguistics. Amsterdam: John Benjamins, pp. 21-37.

Bosque, Ignacio (2001). «Adjective Position and the Interpretation of Indefinites». In: Gutiérrez-Rexach, Javier; Silva-Villar, Luis (eds.). Current Issues in Spanish Syntax and Semantics. Berlin: Mouton De Gruyter, pp. 17-37.

Bossong, Georg (1997). «Le marquage différentiel de l'objet dans les langues d'Europe». In: Feuillet, Jacques (ed.). Actance et Valence dans les langues d'Europe. Berlin: Mouton De Gruyter, pp. 193-258.

Brugè, Laura (2000). «La realizzazione morfologica del caso accusativo». In Categorie funzionali del nome nelle lingue romanze. Milano: Cisalpino, pp. 193-304.

Brugè, Laura; Brugger, Gerhard (1996). «On the Accusative A in Spanish». Probus 8: $1-51$.

Büring, Daniel (2001). «A Weak Theory of Strong Readings». In: Galloway, Teresa; Spence, Justin (eds.). Proceedings of SALT VI, CLC Publications.

Choi, Hye-Won (1999). Optimizing Structure in Context. CSLI: Stanford.

Chung, Sandra; Ladusaw, William (2004). Restriction and Saturation. Cambridge (Mass.): MIT Press.

Cohen, Ariel; Erteschik-Shir, Nomi (2002). «Topic, Focus, and the Interpretation of Bare Plurals». Natural Language Semantics 10. 125-165.

Company, Concepción (2002). «El avance diacrónico de la marcación prepositiva en objetos directos inanimados». In: Bernabé, Alberto et al. (eds.). Presente y futuro de la lingüística en España, vol. II. Madrid: SEL, pp. 146-154.

Dahl, Östen; Fraurud, Kari (1996). «Animacy in Grammar and Discourse». In: Fretheim, Thorstein; Gundel, Jeannette (eds.). Reference and Referent Accessibility. Amsterdam: John Benjamins, pp. 47-64.

Delbecque, Nicole (1999). «La transitivité en espagnol: deux constructions plutôt qu'une». Verbum 21, 1: 49-65.

Delfitto, Denis; Corver, Norbert (1998). «Feature Primitives and the Syntax of Specificity». Rivista di Linguistica 10.2: 281-334.

Diesing, Molly (1992). Indefinites. Cambridge (Mass.): MIT Press.

Enç, Mürvet (1991). «The Semantics of Specificity». Linguistic Inquiry 22: 1-25.

Erteschik-Shir, Nomi (1997). The Dynamics of Focus Structure. Cambridge: Cambridge University Press.

Escandell-Vidal, M. Victoria; Leonetti, Manuel (2000). «Categorías funcionales y semántica procedimental». In: Martínez Hernández, Marcos et al. (eds.). Cien años de investigación semántica: de Michel Bréal a la actualidad, vol. I. Madrid: Ediciones Clásicas, pp. 363-378.

Farkas, Donka (1995). «Specificity and Scope». In: Nash, Lea; Tsoulas, Georges (eds.). Actes du Premier Colloque Langues \& Grammaire. Paris. 119-137.

Farkas, Donka (2001). «Vers une typologie sémantique des syntagmes nominaux». In: Kleiber, Georges; Laca, Brenda; Tasmowski, Liliane (eds.). Typologie des groupes nominaux. Presses Universitaires de Rennes, pp. 17-46. 
Farkas, Donka (2002). «Specificity Distinctions». Journal of Semantics 19: 1-31.

Farkas, Donka; von Heusinger, Klaus (2003). «Stability of Reference and Object Marking in Romanian». UC Santa Cruz / Universität Stuttgart, unpublished manuscript.

Farkas, Donka; De Swart, Henriëtte (2003a). The Semantics of Incorporation: from Argument Structure to Discourse Transparency. Stanford: CSLI.

Farkas, Donka; De Swart, Henriëtte (2003b). «Incorporation, Plurality, and the Incorporation of Plurals: a Dynamic Approach», this volume.

Fauconnier, Gilles (1984). Espaces mentaux. Paris: Minuit.

Franco, Jon; Mejías-Bikandi, Errapel (1999). «The Presuppositionality Condition and Spanish Clitic-Doubled Objects». In: Authier, Jean-Marc; Bullock, Barbara; Reed, Lisa (eds.). Formal Perspectives on Romance Linguistics. Amsterdam: John Benjamins, pp. 107-119.

Gierling, Diana (1997). «Clitic Doubling, Specificity and Focus in Romanian». In: Black, James; Motapanyane, Virginia (eds.). Clitics, Pronouns and Movement. Amsterdam: John Benjamins, pp. 63-85.

Geurts, Bart (2002). «Specific Indefinites, Presupposition and Scope». In: Baüerle, Rainer; Reyle, Uwe; Zimmermann, Thomas E. (eds.). Presuppositions in Discourse. Oxford: Elsevier.

Haspelmath, Martin (1997). Indefinite Pronouns. Oxford: Clarendon Press.

von Heusinger, Klaus (2001). «Cross-linguistic Implementations of Specificity». In: Jaszczolt, Kassia; Turner, Ken (eds.). Meanings in Contrast: the Cambridge Papers, vol. II. Amsterdam: John Benjamins, pp. 405-421.

von Heusinger, Klaus (2002). «Specificity and Definiteness in Sentence and Discourse Structure». Journal of Semantics 19: 245-274.

von Heusinger, Klaus; Kaiser, Georg (2003). «The Interaction of Animacy, Definiteness and Specificity in Spanish». In von Heusinger, Klaus; Kaiser, Georg (eds.). Proceedings of the Workshop «Semantic and Syntactic Aspects of Specificity in Romance Languages», Arbeitspapier 113. Fachbereich Sprachwissenschaft. Universität Konstanz, pp. 41-65.

Jacobs, Joachim (2001). «The Dimensions of Topic-Comment». Linguistics 39-4: 641-681. Jäger, Gerhard (1995a). «Weak Quantifiers and Information Structure». NELS 25: 303-318.

Jäger, Gerhard (1995b). «Topic, Scrambling and Aktionsart». In: Kohlhof, Inga; Winkler,

Susanne; Drubig, Hans (eds.): Proceedings of the Göttingen Focus Workshop. Tübingen. 19-34.

Jäger, Gerhard (2001). «Topic-Comment Structure and the Contrast Between Stage Level and Individual Level Predicates». Journal of Semantics 18: 83-126.

Karimi, Simin (1990). «Obliqueness, Specificity, and Discourse Functions: Râ in Persian». Linguistic Analysis 20, 3-4: 139-191.

Karimi, Simin (1996). «Case and Specificity: Persian Râ Revisited». Linguistic Analysis 26: 174-194.

Karimi, Simin (1999). «A Note on Parasitic Gaps and Specificity». Linguistic Inquiry 30: 704-713.

Karimi, Simin (ed.)(2003). Word Order and Scrambling. Oxford: Blackwell.

Laca, Brenda (1987). «Sobre el uso del acusativo preposicional en español». In: Pensado, Carmen (ed.). El complemento directo preposicional. Madrid: Visor, pp. 61-91. 
Laca, Brenda (1990). «Generic Objects: Some More Pieces of the Puzzle». Lingua 81: 25-46.

Laca, Brenda (1996). «Acerca de la semántica de los plurales escuetos del español». In: Bosque, Ignacio (ed.). El sustantivo sin determinación. La ausencia de determinante en la lengua española. Madrid: Visor, pp. 241-268.

Laca, Brenda (1999). «Presencia y ausencia de determinante». In: Bosque, Ignacio; Demonte, Violeta (eds.). Gramática Descriptiva de la Lengua Española, I. Madrid: Espasa-Calpe, pp. 891-928.

Lazard, Gilbert (1982). «Le morphème râ en perse et les relations actancielles». Bulletin de la Société de Linguistique de Paris 73: 177-207.

Leonetti, Manuel (1998). «A Relevance-Theoretic Account of the Property Predication Restriction». In: Jucker, Andreas; Rouchota, Villy (eds.). Current Issues in Relevance Theory. Amsterdam: John Benjamins, pp. 143-169.

Leonetti, Manuel (1999). «El artículo». In: Bosque, Ignacio; Demonte, Violeta (eds.). Gramática Descriptiva de la Lengua Española, I. Madrid: Espasa-Calpe, pp. 787-890.

Lidz, Jeffrey (1999). «The Morphosemantics of Object Case in Kannada». In: Proceedings of WCCFL 18. Sommerville (Mass.): Cascadilla Press.

Lyons, Christopher (1999). Definiteness. Cambridge: Cambridge University Press. Martín, Juan (1999): «The Syntax and Semantics of Spanish Accusative $a »$. In: GutiérrezRexach, Javier; Martínez-Gil, Fernando (eds.). Advances in Hispanic Linguistics, vol. 2. Sommerville: Cascadilla Press, pp. 469-485.

McNally, Louise (1995). «Bare Plurals in Spanish are Interpreted as Properties». In: Morrill, Glyn; Oehrle, Richard (eds.). Formal Grammar. Barcelona: Universitat Politècnica de Catalunya, pp. 197-222. (Also in this volume).

Meinunger, André (2000). Syntactic Aspects of Topic and Comment. Amsterdam: John Benjamins.

Melis, Chantal (1995). «El objeto directo personal en El Cantar de Mio Cid. Estudio sintáctico-pragmático». In: Pensado, Carmen (ed.). El complemento directo preposicional. Madrid: Visor, pp. 133-163.

Milsark, Gary (1977). «Towards an Explanation of Certain Peculiarities in the Existential Construction in English». Linguistic Analysis 3: 1-30.

Moreno, Norberto; Pérez, Isabel (2001). «Information Structure and the Referential Status of Bare Plurals». ZAS Papers in Linguistics 23: 159-170.

Nakanishi, Kimiko (2002). «Scope Encoding of Indefinite NPs in Japanese». In: von Heusinger, Klaus; Kempson, Ruth; Meyer-Viol, Wilfrid (eds.). Proceedings of the Workshop "Choice Functions and Natural Language Semantics». Arbeitspapier Nr. 110, Fachbereich Sprachwissenschaft, Universität Konstanz. 141-165.

Neeleman, Ad; Reinhart, Tanya (1998). «Scrambling and the PF Interface». In: Butt, Miriam; Geuder, Willem (eds.). The Projection of Arguments. Stanford: CSLI, pp. 309-351.

Nikolaeva, Irina (2001). «Secondary Topic as a Relation in Information Structure». Linguistics 39.1: 1-49.

Pensado, Carmen (1995). «El complemento directo preposicional: estado de la cuestión y bibliografía comentada». In: Pensado, Carmen (ed.). El complemento directo preposicional. Madrid: Visor, pp. 11-59. 
Pesetsky, David (1987). «Wh-in-Situ: Movement and Unselective Binding». In: Reuland, Eric; ter Meulen, Alice (eds.). The Representation of (In)definiteness. Cambridge (Mass.): MIT Press, pp. 98-129.

Picallo, Carme (1994). «A Mark of Specificity in Indefinite Nominals». Catalan Working Papers in Linguistics 4.1: 143-167.

Portner, Paul; Yabushita, Katsuhiko (2001): «Specific Indefinites and the Information Structure Theory of Topics». Journal of Semantics 18: 271-297.

Prince, Ellen (1992). «The ZPG letter: Subjects, Definiteness, and Information Status». In: Thompson, Sandra; Mann, William (eds.). Discourse Description: Diverse Linguistic Analyses of a Fund-raising Text. Philadelphia: John Benjamins, pp. 295-325.

Rapoport, Tova (1995). «Specificity, Objects and Nominal Small Clauses». In: Cardinaletti, Anna; Guasti, Maria Teresa (eds.). Syntax and Semantic, 28: Small Clauses. New York: Academic Press.

Raposo, Eduardo; Uriagereka, Juan (1995). «Two Types of Small Clauses (Towards a Syntax of Theme/Rheme Relations)». In Cardinaletti, Anna; Guasti, Maria Teresa (eds.). Syntax and Semantics, 28: Small Clauses. New York: Academic Press, pp. 179-206.

Rouchota, Villy (1994). «On Indefinite Descriptions». Journal of Linguistics 30: 441-475.

Sadler, Misumi (2002). «From a Pragmatic Marker to a Direct Object Marker», Studies in Language 26: 243-281.

Sánchez López, Cristina (1995). «Construcciones concesivas con para». Revista Española de Lingüística 25: 99-123.

Shokouhi, Hussein; Kipka, Peter (2003). «A Discourse Study of Persian râ». Lingua 113: 953-966.

Sperber, Dan; Wilson, Deirdre (1986). Relevance. Oxford: Blackwell.

Suñer, Margarita (1988): «The Role of Agreement in Clitic-Doubled Constructions». Natural Language and Linguistic Theory 6: 391-434.

Torrego, Esther (1998). The Dependencies of Objects. Cambridge (Mass.): MIT Press. Torrego, Esther (1999). «El complemento directo preposicional». In: Bosque, Ignacio;

Demonte, Violeta (eds.). Gramática Descriptiva de la Lengua Española, II. Madrid:

Espasa-Calpe, pp. 1779-1805.

Vallduví, Enric (1992). The Informational Component. New York: Garland.

Van Geenhoven, Verle (1998). Semantic Incorporation and Indefinite Descriptions. Stanford: CSLI.

Van Geenhoven, Verle; McNally, Louise (to appear). «On the Property Analysis of Opaque Complements», Lingua.

Wilson, Deirdre; Sperber, Dan (1993). «Linguistic Form and Relevance». Lingua 93: $1-25$.

Yamamoto, Mutsumi (1999). Animacy and Reference. Amsterdam: John Benjamins. Yeom, Jae-Il (1998). A Presuppositional Analysis of Specific Indefinites. New York: Garland. 